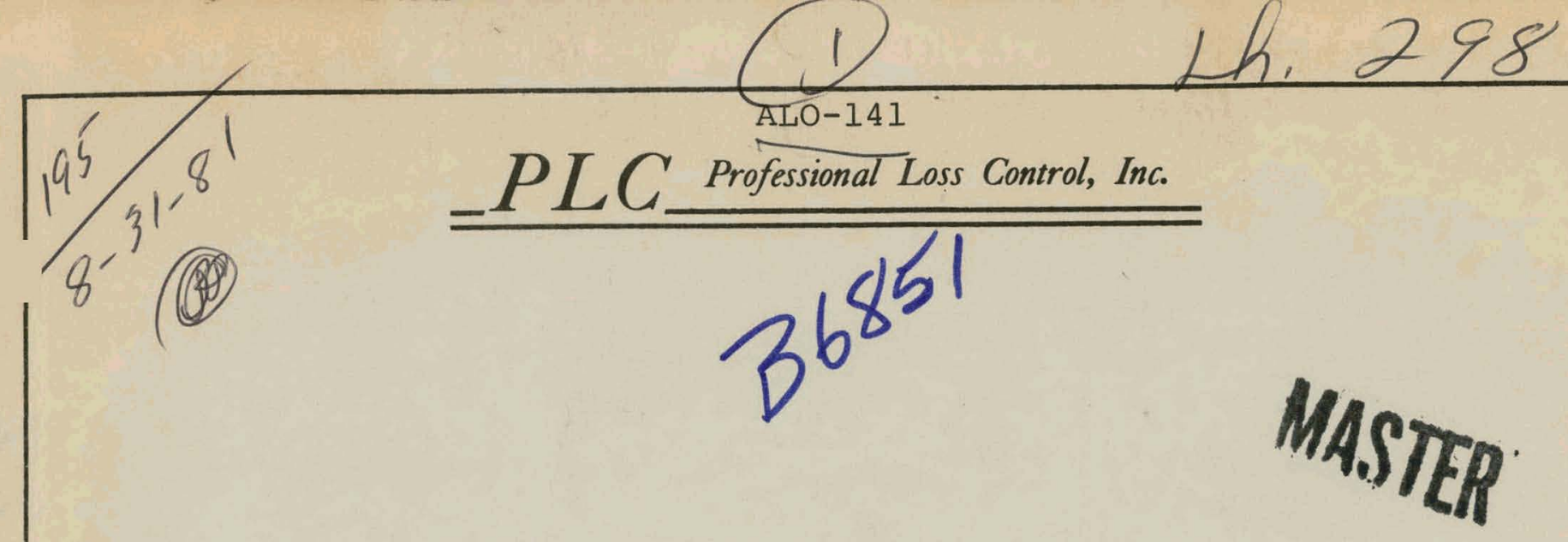

\title{
Effectiveness of Fire-Detection Systems \\ in Light-Water-Reactor Facilities
}

for

Sandia Laboratories

October 1980

Printed August 1981

Philip J. DiNenno

Kenneth W. Dungan 


\section{DISCLAIMER}

This report was prepared as an account of work sponsored by an agency of the United States Government. Neither the United States Government nor any agency Thereof, nor any of their employees, makes any warranty, express or implied, or assumes any legal liability or responsibility for the accuracy, completeness, or usefulness of any information, apparatus, product, or process disclosed, or represents that its use would not infringe privately owned rights. Reference herein to any specific commercial product, process, or service by trade name, trademark, manufacturer, or otherwise does not necessarily constitute or imply its endorsement, recommendation, or favoring by the United States Government or any agency thereof. The views and opinions of authors expressed herein do not necessarily state or reflect those of the United States Government or any agency thereof. 


\section{DISCLAIMER}

Portions of this document may be illegible in electronic image products. Images are produced from the best available original document. 
EFFECTIVENESS OF FIRE-DETECTION SYSTEMS

IN LIGHT-WATER-REACTOR FACILITIES

Philip J. DiNenno

Kenneth W. Dungan

Prepared by

$\checkmark$ TLC Professional Loss Control, Inc.

P. O. Box 446

Oak Ridge, Tennessee 37830

Prepared for

U. S. Department of Energy

Light Water Reactor Safety Technology Management Center

Sandia Natipnal Laboratories

Albuquerque, New Mexico 87185

sponsored by

U. S. Department of Energy

Division of Nuclear Power Development

Washington, D. C. 20545

Work performed under Sandia Contract No. 49-1716

Submitted: October 1980

Printed: August 1981

$i-i i$

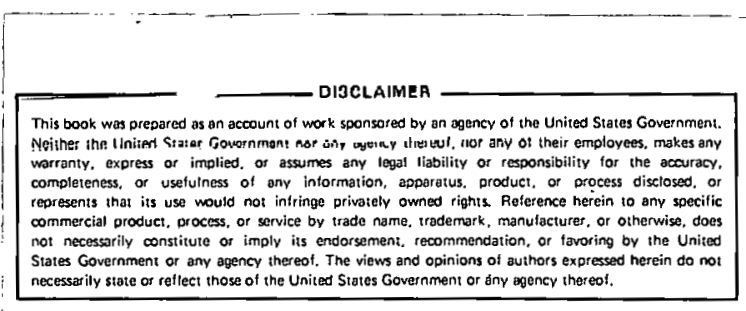

OISTRIBUTION OF THIS OOCUMENT IS UNLIMITEP 
(1) TId - $4500-4 k-78$

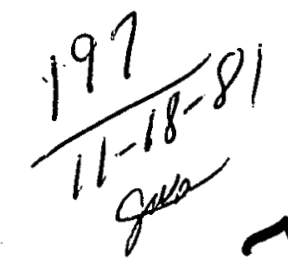

October 27,1981

\section{Sandia Laboratories}

Albuquerque, New Mexico 87115

\section{ALO- 141 Errate}

DISTRIBUTION

\section{$m 81029465$}

Subject: P. J. DiNenno, K. W. Dungan, Effectiveness of Fire Detection Systems in Light water Reactor Facilities, Professional Loss Control, Inc., Oak Ridge, Tennessee; printed by Sandia National Laboratories, Albuquerque, New Mexico, ALO-141, August 1981.

The legal disclaimer page was inadvertently omitted from the subject report. Please replace pages $i / i i$ with the attached corrected page $(s)$.

Attachment

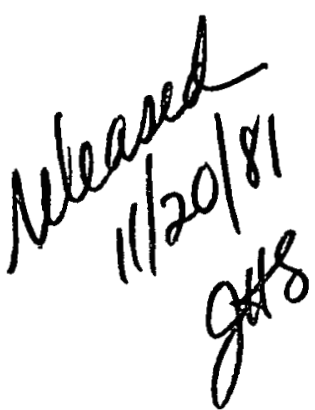


EFFECTIVENESS OF FIRE DETECTION SYSTEMS

IN LIGHT WATER REACTOR FACILITIES

Philip J. DiNenno

Kenneth W. Dungan

\author{
Prepared by \\ PLC Professional Loss Control, Inc. \\ P. O. Box 446 \\ Oak Ridge, Tennessee 37830 \\ Prepared for \\ U. S. Department of Energy \\ Light Water Reactor Safety Technology Management Center \\ Sandia National Laboratories \\ Albuquerque, New Mexico 87185 \\ Sponsored by \\ U. S. Department of Energy \\ Division of Nuclear Power Development \\ Washington, D. C. 20545
}

Work performed under Sandia Contract No. 49-1716

Submitted: October 1980

Printed: August 1981 


\section{NOTICE}

This report was prepared as an account of work sponsored by an agency of the United States fovernment. Neithor the United States nor any agency thereof, nor any of their employees, makes any warranty, expressed or implied, or assumes any legal liability ol respunsibllity for any third party's use or the results of such use of any information, apparatus, product or process disclosed in this report, or represents that its use by such third party would not infringe privately owned rights.

Printed in the United States of America

Available from

National Telluilual Information Service

U. S. Department of Commerce

5285 Port Royal Road

Springfield, VA 22161

Price: Printed Copy $\$ 8.00 ;$ Microfiche $\$ 3.00$ 
DISTRIBUTIOIN :

TID-4500 - UC-78 (197 copies).

J. H. Carlson, $\mathrm{NE}-540$ (5)

Office of Nuclear Power Systems

U. S. Department of Energy

Mail Stop B-107

Washington, DC 20545

J. D. Griffith, Acting Director

Office of Nuclear Power Systems, NE-540

U. S. Department of Energy

Mail Stop B-107

Washington, DC 20545

A. C. Millunzi, Team Leader

Safety Research and Development Team, NE-540

office of Nuclear Power Systems

U. S. Department of Energy

Mail Station B-107

washington, DC 20545

J. Yevick, iNE-540

Safety Research and Development Team

Office of Nuclear Power Systems

U. S. Department of Energy

Mail Station B-107

Washington, DC 20545

Leo Beltracchi

U. S. Nuclear Regulatory Commission

Division of Systems Safety P-350

office of inuclear Reactor Regulations

Washington, DC 20555

Raymond DiSalvo, Branch Chief

Operations Safety Research

U. S. Nuclear Regulatory Commission

Mail Stop 1130 SS

Washington, DC 20555

George Knighton, Branch Chief

Research \& Standards Coordination

U. S. Nuclear Regulatory Commission

Mail Stop P-538

washington, DC 20555 
Distribution (cont'd):

R. Minogue, Director

Office of Nuclear Regulatory Research

U. S. Nuclear Regulatory Commission.

Mail stop 1130 ss

Washington, DC 20555

D. Notley

Office of Nuclear Regulatory Research

U. S. Nuclear Regulatory Commission

Mail stop l130ss

Washington, DC. 20555

R. Feit

office of Nuclear Regulatory Research

U. S. Nuclear Regulatory Commission

Mail stop 1130ss

Washington, 'DC 20555

Robert L, Ferguson

Division of systems safety

office of Nuclear Reactor Regulation

U. S. Nuclear Regulatory Commission

Washington, DC. 20555

D: Okrent

University of California

Chemical; Nuclear, and Thermal Engineering

5532 Boelter Hall

Los Ángeles, CA 90024

W. Lowenstein

Electric pówer Research Inçtitute

3412 Hillview Avenue

P. O. Box 10412

Palo Alto, CA 94303

K. W. Dungan : (20)

Professional Loss Control

P. O. Box 446

Oak Ridge, TN 37830

J. L. Bryan

Professor and Department Head

Department of Fire Protection Engineering

University of Maryland

College Park, MD 20742

J. A. Milke

Research Assistant

Department of Fire Protection Engineering

University of Maryland

College Park, MD 20742 
Distribution (cont'd):

D. Perrault

Fire Protection Engineer

Bechtel Power Corp.

15740 Shady Grove Road

Gaithersburg, MD 20760

E. A. Sawyer

Yankee Atomic Electric

1671 Worchester Road

Framingham, MA 01701

Chris Volman

Fire Protection Engineer

Paducah Gaseous Diffusion Plant

P. O. Box 1410

Paducah, KY 42001

R. Bukowski

Center for Fire Research

National Bureau of Standards

Washington, DC 20234

N. Chekotis

Pytronics Corp.

8 Ridgedale Avenue

Cedar Knolls, NJ 079.27 .

G. Patrissi

Florida Power Corp.

Crystal River Nuclear Plant

P. O. Box 1240

Crystal, River, FL 32629

R. Schmiedel

Florida Power Corporation

P. O. Box 14042

St. Petersburg, FL 33733

W. Klein

Florida Power \& light

Turkey Point Nuclear Plant

P. O. Box 529100

Miami, FL 33152

D. Keigher

Fire Protection Consultant

Los Alamos Scientific Laboratory

P. O. Box 1663

Los Alamos, NM 87545 
Distribution (cont'd) :

D. Rosh

Consolidated Edison of N.Y.

Room 1014

4 Irving Place

New York, NY 10003

E. Budnick

Center for Fire Research

National Bureau of Standards

Washington, DC 20234

J. U. Allen, F.E.

Director, Fire Protection Engineering

Insurance Company of North America

Loss Control Division

1600 Arch Street

Philadelphia, PA 19103

L. R. Hathaway, Manager

Puolic Utility Unit

$M$ \& $M$ Protection Consultants

222 South Riverside Plaza

Chicago, IL 60606

H. $K$. Hasegawa

Fire Science Group, Hazards Control Department

University of California

P. O. Box $5305, \mathrm{~L}-442$

Livermore, CA 94550

B. J. Gerwe

Fire Protection Engineer

Gilbert Associates, Inc.

Reading, PA 19603

D. E. Roland

Susquehanna S.E.S.

Pennsylvania Power \& Light Co.

P. $0, \quad B \cap \times 467$

Berwick, PA 18603

R. J. O'Laughlin

Union Carbide Corporation

Nuclear Division

Mail Stop 003

Post Office Box $Y$

Oak Ridge, TN 37830 
Distribution (cont'd):

J. Echternacht, Manager

Wormald Fire Engineering 5255 Langfield Road, Suite F Houston, TX 77040

B. Melly

Fire Protection Engineer

Systems Division

Black \& Veach

P. O. Box 8405

Kansas City, MO 64114

D. Harbert

United Engineers \& Constructors

c/o Carolina Power \& Light

Brunswick Steam Electric Plant

P. O. Box 1087

Southport, NC 28461

R. R. Cholin, President

Firetek Corp.

53 Thomas Road

Hawthorne, NJ 07306

J. Corcoran

Niagara Mohawk Power Corp.

300 Erie Boulevard West

Syracuse, NY 13202

J. L. Dymek

Florida Power \& Light

P. O. Box 529100

Miami, FL 33010

H. Taylor

Fire Protection Specialist

Power Generation Department

Georgia Power Co.

230 Peachtree Street, 16th Floor

Atlanta, GA 30302

A. D. J. Sanchez, Mechanical Engineer

Generation Engineering Department

Portland General Electric

121 S.W. Salmon Street

Portland, OR 97204 
Distribution (cont'd) :

P. D. Lund

Society of Fire Protection Engineers

60 Batterymarch Street

Boston, MA 02110

J. Stamp

F. E. Moran, Inc.

P. O. Box 551

Northbrook, IL 60062

R. Thompson, Supervisor

Fire Protection Engineering

Tennessee Valley Authority

1650 Chestnut street Tower II

Chattanooga, TN 37401

R. M. H. Terrier, Director

Loss Prevention

Virginia Electric \& Power Co.

1 James River Plaza

P. O. BOX 26666

Richmond, VA 23261

G. W. Powell

Baltimore Gas \& Electric Co.

P. O. Box 1475

Baltimore, MD 21203

B. Cohn

Gage-Babcock

135 Addison Avenue

Elmhurst, IL 60126

R. Pape

IIT Research Inst.

Chemical Division

10 W. 35 th Street

Chicago, IL 60616

J. Rockett

Center for Fire Research

National Bureau of Standards

Washington, DC 20234

B. Williamson

507 Davis Hall

University of California

Berkeley, CA 94720 
Distribution (cont'd) :

Energy Research \& Technology Division

(2)

U. S. Department of Energy

Albuquerque Operations office

Albuquerque, NM 87185

Attn: D. I. Krenz, Director

R. L. Clark

4400

4440

A. W. Snyder

G. R. Otey

4410

4414

4414

D. J. McCloskey

G. B. Varnado

4442

4442

4442

4443

4443

4443

5513

5513

5513

8214

3141

D. L. Berry

W. A. Von Riesemann

D. Dube

L. J. Klamerus

D. A. Dahlgren

P. Shea (20)

J. L. Sprung

D. W. Larson

M. R. Baer

D. D. Cline

M. A. Pound

L. J. Erickson

W. I. Garner

3151

DOE/TIC (Unlimited Release) 


\section{PAGES $\mathrm{i}$ to $\mathrm{ii}$ WERE INTENTIONALLY LEFT BLANK}




\section{TABLE OF CONTENTS}

Title Page

I. Introduction. . . . . . . . . . ...... 1

II. Application of Fire Detection in Nuclear Power Plants . . 4

III. Existing Methodologies for Design and Evaluation. . . . . . 6

A. Consensus Standards................ 6

B. Independent Testing............... 10

C. In-Situ Testing.................. 12

D. Quality Assurance ................. 13

IV. Technical Basis for the Evaluation of Fire Detection

Systems .................. . 16

A. Reliability of Detection Systems. . . . . . . . . 16

1. Introduction. . . . . . . . . . . . 16

2. False and Spurious Alarms ........... . 20

3. Quantitative Reliability Analysis........ . 21

B. Detector Response .. . . . . . . . . . . . . 24

1. Heat Detectors. . . . . . . . . . . . . 25

2. Smoke Detectors .... . . . . . . . . . 27

Ionization.: . . . . . . . . . . . . . 27

Photoelectric Detectors . . . . . . . . . 29

Data on Smoke Properties. . . . . . . . . . 31

3. Buoyant Plume/Ceiling Jet Models. . . . . . . 37

4. Environmental Variables........... . 46

Temperature Stratification. ........55

Ventilation ............... 53

Room Geometry .............. . . 57

Combined Effects.............. . 57

5. Semi-Empirical Studies. . . . ........ 59

V. Proposed In-Situ Test Methods .............. 69

A. Evaluation of Detector Response Parameters. . . . . . . 70

B. Evaluation of Smoke/Heat Transport to the Detector. . . 70

1. Use of Small Heat Source to Simulate Plume. . . . . 71

2 . Use of Test Gas to S1mulate Plume........ . 79

C. Further Work. . . . . . . . . . . . . . 81

VI. Conclusions .. . . . . . . . . . . . . . . 84

VII: Recommendations ... . . . . . . . . . . . 87

References. .. . . . . . . . . . . . . . . 


\section{INTRODUCTION}

This project is part of a larger effort sponsored by the U.S. Department of Energy to develop evaluation methodologies for regulatory assistance. The problems and methodologies discussed in this report, al though developed in the context of light water reactor nuclear power plants, are not unique to those facilities and apply equally to all industrial environments, including those presented by emerging energy technologies.

The purpose of this report is to present a critical review of methods for evaluating fire detection system capabilities. These capabilities must include some measurement of success. The problem of evaluating the effectiveness in terms of probability of success or "certainty" of success of fire detection systems must be answered either to enable the correct selection of system when a need is identified, or to assess the acceptability of an existing system in meeting an identifjed need. These methods are complementary to a hazards analysis, which identifies the need, but can be quite independent in their deveropment and use.

The problem can be broken down into the basic categories of "reliability" and "adequacy." In general terms, this means (1) will the system operate and when, and (2) if the system(s) operates as intended, will it accomprish its design objective.

For fire detection systems, reliability considerations must be applied 
to circuitry, control equipment (such as relays, alarms, etc.) and the detectors themselves. The question of adequacy must consider detector sensitivity, environmental variables and hazard variables. Techniques, whether probabilistic, deterministic, empirical, or otherwise, must address these fundamental considerations.

Any methnd for solving the problem of fire detection systems capability must also meet the restraints of being consistent (reproducible when applied by different engineers), accurate (provide acceptable results with sufficient reliability), and simple (usable as a common evaluation tool).

This report covers the existing approaches to design and evaluation of detection systems. These include consensus codes and standards, independent testing approval, in-situ testing, and analytical ur einjplrical methodologies. The advantages and limitations of these current techniques are discussed. In addition, in-situ test methods are proposed.

In order to identify the necessary data required to evaluate detection systems, a review of the parameters which identffy reliabilily and adequacy is incorporated. Reliability is defined in terms of "failure on demand" and also false nr "spurious" actuations. System adequacy is discussed in terms of detector sensitivity, environmental variables and hazard variables.

From this review, conclusions are drawn as to the "state-of-the-art" of 
detection system design. Recommendations identify those gaps in existing data which must be filled by testing or engineering analysis.

It is important to note that the systems discussed in this report are limited to those "standard" types currently installed in LWR plants in the United States. Predominately, these include thermal devices, ionization dẹtectors, and photoelectric smoke detectors. Flame detectors are not treated in detail due to their limited application. New developments in detection and alarm system hardware hold promise for the future. However, these interesting developments are beyond the scope of this review. 


\section{APPLICATION OF FIRE DETECTION IN NUCLEAR POWER PLANTS}

Before embarking on any detailed discussion of fire detection systems, evaluation, it is essential to identify the functions or importance of those systems to the safety of nuclear power plants. With the application of "defense in depth" fire protection philosophy in nuclear power plants, fire detection is often relegated to a "back-up" fire prevention (by design and operation) and separation criteria (for redundancy). The stated philosophy becomes first, to prevent fires by designing away ignition sources and combustibles to the greatest extent practical and controlling administratively any operator action or plant modiffcations that might circumvent this preventive design. Next, assuming fire can and will still occur because of intentional or accidental deviations from fire prevention measures, separation of redundant systems, essential to assure the safety of the plant, is maintained with elther fire barriers (preferred), or spatial separation. Fire detection and suppression systems are then considered a "back-up" to other design and operating features when limiting the fire protection objectives solely to safe-shutdown considerations for new plants.

Unfortunately, this description of the role of fire detection for nuclear power plants oversimplifies several critical issues which must be understood. These issues include, but are not limited to, the following:

1. Many existing plants rely on fire safety measures other than separation criteria or in combination with separation criteria where complete fire barriers are not practical. 
These measures often include cable coatings, partial barriers or flame shields, or other passive measures which retard the growth or spread of a fire at the onset of fire damage.

2. Uncertainties have been identified as to the method of establishing acceptable separation criteria from a fire protection standpoint.

3. From economic and power demand standpoints, neither the utilities industries, the consumers, nor the national economy can afford the potential damage and loss of power production from an undetected fire in a nuclear power plant.

The issue of fire detection for Nuclear Power Plants distills down to two questions: (1) How exact must the definition of the system design criteria be? (2) How exact can the definition and subsequent verification of system design criteria and installations be? The first question is a policy matter which can only be answered by a detailed fire hazards analysis in combination with a statement of acceptability of risk. The second question is a technical question which can be answered by identifying the state-of-the-art of fire detection design and evaluation. It is of value to understand the importance of the technical limitations of current detection system design and evaluation methods in establishing design objectives and policies regarding acceptability of risk. This report. focuses on answering this second question. 
III. EXISTING METHODOLOGIES FOR DESIGN AND EVALUATION

The existing design and evaluation guidance advocated by the USNRC for LWR plants is the consensus standards developed by the National Fire Protection Association (NFPA), NFPA \#72D ( 1 ), Proprietary Protective Signaling systems, and NFPA \#72E ( 2 ), Automatic Fire Detectors. The Standard Review Plan 9.5-1 (3) and proposedd Regulatory Guide 1.120 (4) reference these documents but do not specify a particular edition. Consensus standards are dynamic and are updated to meet changing technology. The standards referenced by NRC are two of the more volatile NFPA standards because of the rapid advances in equipment and technology.

By reference and requirements, these NFPA Standards depend to a great degree on approvals of independent testing laboratories, acceptance testing, and judgment on the part of the user. For these reasons, this section discusses not only the consensus standards, but also approval testing and current methods of in-situ testing by evaluation engineers.

\section{A. Consensus Standards}

Standards regarding alarm systems, NFPA \#72D, are concerned with the reliability of the signal carrying and transmitting hardware. In that regard alarm system requirements will be addressed in the discussion of rellability. A point worth expanding, however, regarding the selertion of a specific edition of a standard, is the recent change in the NFPA \#72D standard. During the development of both the Standard Review Plan 
9.5-1 and Reg. Guide 1.120, the 1975 edition of the standard was in effect. Therefore, references in these NRC documents intended for clarification of their 1975 edition reference "Class A" circuits. In 1979 revision of NFPA \#720, the entire standard was rewritten which totally el:iminated the reference to the term "Class $A . "$ The new edition is written to reflect the variety of options available for alarm systems and, therefore, is more general in its requirements. This in turn requires more judgment on the part of the designer. However, these judgments are based on a straight forward assess ment of reliability requirements.

The standard for selection and placement of fire detectors, NFPA \#72E, has also been rewritten since the issuance of NRC Guidelines. Since the technical question regarding the selection and placement of detectors is more complex than that of alarm systems, the major emphasis of this review is detectors. The 1978 edition of the NFPA \#72E standard completely reviscd Chapter 4, Smoke Sensing Fire Detectors, and added a new Chapter 6, Gas Sensing Fire Detectors, since the issuance of NRC guidance based on the 1974 edition.

The limitations of the design and evaluation guidance provided by the' NRC documents and the NFPA \#72E - 1974 are described by Berry (5) in an excellent review. Many of these limitations apply equally to the later edition. It is important to realize that the NFPA committee on 
Detection Devices recognizes the limitations of this standard and are aggressively pursuing answers to the technical uncertainties which this report identifies. The Committee states in the preface to NFPA \#72E 1978, "the Committee recognizes the need for additional fire research. The Fire Vetection Inst1tute is expected lo perform these needed tasks. The current edition of this standard is based on the best information known to date. The standard will be refined as results and additional information are received and studied." The revision and updating of this standard raises interesting policy questions to regulatory agencies like the NRC regarding the acceptability of existing detection systems in LWR plants. Methods must be available to assess the value of system changes on improved plant safety before system changes are required to comply with revised standards. However, there is no reason to believe that the Fire Detection Institute will sponsor research relevant to LWR facilities.

The application of NFPA \#72E to LWR facilities must also consider the committee's intentions as outlined in the Purpose and Scope of the standard. Paragraph 1-1.2 of the Purpose states, "This standard is intended for use by persons knowledgable of fire protection." The discussion in this section identifies what information is necessary. to make "knowledgable" detection system designs and evaluations. The Scope states in paragraph 1-2.4:

"Nothing in this standard is intended to prevent the use of new methods or devices providing sufficient technical data 
are submitted to the authority having jurisdiction to demonstrate that the new method or device is equivalent in quality, effectiveness, durability and safety to that prescribed by this standard."

This report outlines what technical data is required to evaluate new methods as compared to existing methods of detection.

Chapter 2-5, "Common Requirements," outlines basic requirements for all detection devices. Paragraph 2-5.1.1 requires all fire detection devices to be listed or approved for the purpose for which they are intended. This cross reference to approval laboratories punctuates the need for a thorough understanding of the approval test methods in order to design or evaluate detection systems. These tests will be discussed below. Additionaliy, Paragraph 2-5.2.1 requíres acceptance tests by stating, "Upon completion of the Installation, satisfactory test of the fire detectors shall be made in the presence of a representative of the authority having jurisdiction." Testing is further defined in Chapter 8 which places great emphasis on "manufacturer's instructions." The problems of in-situ testing are further defined below.

It is not the intent of this report to reiterate the guidance outlined in NFPA \#72E-1974 or NFPA \#72E-1978, but rather to point out the qualitative nature of the guidance. To emphasize this point, the example of location 
and spacing criteria of smoke detectors is used. In Paragraph 4-3.1 the following guidance is given: "The location and spacing of smoke detectors shall result from an evaluation based on engineering judgment supplemented by the guidelines detailed in this Standard. Ceiling shape and surfaces, ceiling height, configuration of contents, burning characteristics of combustible materials present, and ventilation are some of the conditions that shall be consldered." The application of this guidance requires an understanding of environmental varfables and hazard variables and their interaction in the area be protected. There is no coherent documentation available which synthesizes this information for use by sys tem designers.

\section{B. Independent Testing}

As outlined above, detectors must be approved or 1 isted to meet the requirements of NFPA \#72E-1978. Most importantily, these appróváls must be for the intended applications. For this reason it is essential that designers and evaluators be familiar with the test conditions of the approvals laboratories.

Independent laboratories which approve or list fire detection devices in this country are Underwriters Laboratories (UL) and Factory Mutual Research (FM). Berry (5) outlined UL test methods in effect in 1977 which included UL 167 and UL 168 for ionization and photoelectric respectively, $(6,7)$ and UL 521 - Fire Detection Thermostats (8). Since his review, UL 167 and UL 168 have been replaced by a new test, UL 268, "Smoke 
Detectors for Fire Protection Signaling Systems," (9) and a fourth edition of UL 521 was issued in 1978.

The fire tests outlined in Sections 33 and 34 of UL 268 are to take effect March 30, 1981. These tests will expose both types of smoke sensing detectors to four fire conditions and a smoldering wood test. The four fires consist of Paper Fire - Test A, shredded newsprint; Wood Fire - Test B, kiln-dried fir strips; Gasoline Fire - Test C, $30 \mathrm{ml}$. of regular leaded gasoline; and Polystyrene Fire - Test D, foam polystyrene. The tests are conducted in a room, 22 feet by 36 feet by 10 feet high, with a smooth ceiling and essentially zero air movement. The base time for acceptance is 4 minutes for Test $A$ and Test $B, 3$ minutes for Test $C$, and 2 minutes for Test $D$. The smoldering test consists of ponderosa pine sticks placed on a hot plate. The test is. conducted in the same room. The acceptance criteria is that the detectors must alarm before obscuration exceeds $7 \%$ per foot. Sensitivity tests are also conducted in a chamber 41-3/4 inches long by 11-1/2 inches high by 18-1/8 inches wide, with a range of horizontal laminar air flow from 30 to $150 \mathrm{ft} . / \mathrm{min}$. Tests use smoke of a cotton lamp wick and a small kerosene lamp to evaluate detector sensitivity. Detectors under UL test requirements are also evaluated for stability and reliability as. outlined in UL 268.

Tests conducted on smoke detectors by Factory Mutual Research (FM) are briefly outlined in Approval Standard 3230-3250 (10). The standard 
requires a detector to respond to specified sources of smoke before light obscuration at the detector exceeds $4 \%$ per foot. Although the standard references gray smoke from cotton rope, FM uses 6 types of smoke, one of which is PVC cable insulation. Detectors are cycled through 500 functions and placed in standby for 30 days in a clean air (working-office type) atmosphere to evaluate reliability and sensitivity. These tests are conducted in a test chamber and are small scale.

\section{In-Situ Testing}

The problem of in-situ testing as that of detected response is best described in two parts: (1) Detector response to stimuli, and (2) Transport of stimuli to detector. The "satisfactory" test required in NFPA \#72E-1978 has been applied in LWR plants as a limited detector. response test. These tests consist of introducing a stimuli in the vicinity of the detector. Although this problem applies equally to all types of detectors, the discussion here centers on smoke sensing detectors. This stimuli is often smoke from a cigar or cigarette or an aerosol packaged in spray cans for that purpose. This portion of the test is valuable to assure that detectors are properiy installed but falls short of actually verifying the effectiveness of the design.

Detector response testing has been expanded to include specific types of aerosols. Lee (11) describes the dependence of smoke detector response 
on particle size and outlines a method of testing using an aersol generator. This testing still ignores the transport of the aerosol to the detector.

More importantly, current in-situ test methods do not evaluate the transport of smoke and heat to the detector. Environmental factors in LWR facilities are one of the major reasons for the inability to determine a priori detection system effectiveness--because of the gross effects of environmental conditions on plume and ceiling jet development. The importance of smoke transport is discussed in Section IV.

Due to the importance of in-situ testing to the evaluation of fire detection systems and the shortcomings of existing techniques, a new methodology is proposed in Section $V$.

\section{Quality Assurance}

Attachment No. 6 of the NRC supplementary guidance on "Nuclear Plant Fire Protection Functional Responsibilities, Administrative Controls and Quality Assurance" (12) addresses quality assurance requirements as they relate to fire protection systems and procedures. Regulatory Guide 1.120 refers to NFPA Standards 720 and $72 E$ as reference standards. Deviations from these quality standards are required to be justified. The problem with this approach is that the rationale behind NFPA $72 E$ on detector placement is not documented. As a result, it is difficult to adequately define detection system acceptance and rejection criteria 
for quality assurance. In addition, appropriate standards are often not adhered to even when it is possible to do so.

Control of the purchased materials used in the detection system is generally limited to ensuring that all necessary components are tested and "approved" by a nationally recognized testing laboratory. Such an approach is useful but appropriate quality control is not ensured unless the test conditions and configurations are well understood by the enforcing group. The problems are further complicated by the fact that detector installations are often not installed in a manner which is similar to those in which the detectors were originally tested and approved. For this reason, it is much more difficult for QA/QC personnel to determine the adequacy of the system design and installation arid the validity of the justifications for code deviations.

Factors which especially impact operation of emoke and ionization detectors (which are most often utilized in a nuclear power plant) include: area ventilation rates, air flow patterns, ceiling height, fire size, fire location, detector location with respect to the hazard, type of combustibles involved, ambient air temperatures, obstructions (such as beams) at ceiling level, airborne dust in the area, and background radiation. These plant characteristics will affect the detector response in an ill defined manner because of the lack of appropriate test data and a lack of thorough understanding of the tests which the detectors are normally subjected to. 
For example, paragraph 4-5.1.4 of NFPA 72E limits the ambient temperature that smoke detectors should be installed in to a range of $32^{\circ}$ to $100^{\circ} \mathrm{F}$ unless specifically listed for other temperatures. Underwriters Laboratories Inc. (UL) listings specify $100^{\circ} \mathrm{F}$ as the maximum temperature but offer no guidance for minimum temperatures. Factory Mutual (FM) lists smoke detectors for a range of $32^{\circ}$ to $125^{\circ} \mathrm{F}$. Neither of these references offer any information on the impact of higher or lower temperatures on the devices sensitivity. This particular example may be important because of the number of hot areas in a nuclear power plant.

It is obvious from this example that a complete understanding of approval tests is needed. In addition, supplementary tests may have to be specified in order for quality assurance personnel to determine the effect of the specific plant environment on the operational characteristics of a particular detector. Few, if any, engineers presently possess sufficient knowledge to make even a qualitative decision on the adequacy of a detection system installation.

Additional research and testing are needed to provide the necessary body of information to make intelligent decisions possible on whether deviations frum code installations are beneficial or detrimental to their function. 


\section{TECHNICAL BASIS FOR THE EVALUATION OF FIRE DETECTION SYSTEMS}

\section{A. Reliability of Detection Systems}

1. Introduction

One of the major aspects of the effectiveness of a fire detection system is its reliability. Reliability of the detection systems can be subdivided into the fault categorles shown in Figure 1.

Environmental transients, such as steam leaks, dust aerosol formations, high ventilation rates, etc., are discussed in the section on environmental variables. Further, our discussion will center on the qualitative evaluation of fire detection system reliability. We will also discuss the reliability of the entire detection system including: detectors, wiring, alarm indicating panels, audible alarms, dind cuntrol featurcs of these systems.

A major unresolved issue is the quallitication of detcction system reliability. Obviously, this is a function of the importance of carly fire detection to the overall plant safety system. For example, in many plant safety evaluation reports and fire hazards analysis documentation the action of lhe plant brigote is assumed because of early warning detection. Often the detection system actuation is a prerequisite for automatic suppression system operation. In general, the detection system will form a "back up" function to barrier installation and spacial separation. It is clear, however, that the importance of the detection system 
must be related to the level of reliability required of it. This is an extension of on-going Sandia works in establishing a methodology for the evaluation of plant fire safety (13). These issues are more completely discussed in Section II.

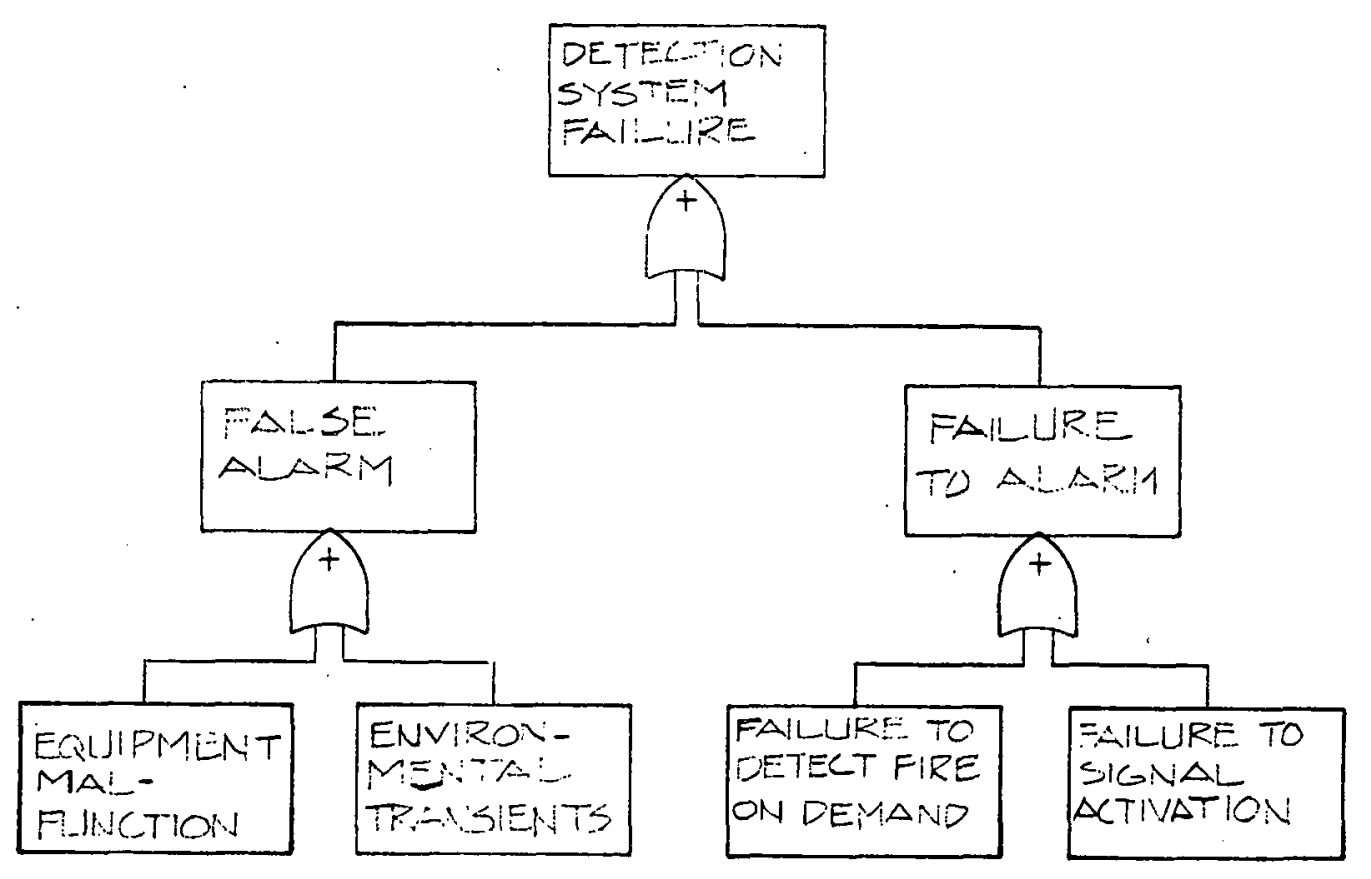

FIGURE 1: Basic Function Fault Type Description for Fire Detection Systems 
The distribution of detector failures, for example, might be expected to be continuous with varying source strengths, i.e., the "sensitivity" of the detector is not a discrete on/off type variable, rather it should be related by some probability distribution of particle size, etc.

Analysis of detection system reliability must include the following cuns ideralions:

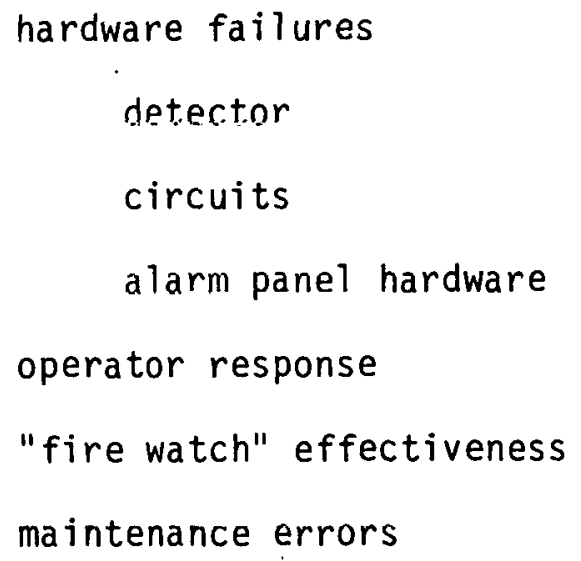

The acceptability of a failure is also a function of whether the fault is detectable (supervised) or if the fault is only detectable during a system test. In the latter case the interval between detection system testing will have significant impact on the detection system reliability. Further, such an analysis permits an evaluation of the maintenance and testing requirements and would serve to validate them. Some variation in reliability is expected between systems but the variation will likely be within the one order of magnitude. The key point is to evaluate the acceptability of the failure rate.

It is worthwhile to mention the unique aspect of nuclear facilities in the requirement for a "fire watch" during a detection system outage in 
specified plant areas. First, this "redundant" safeguard is only available if the fault is detected. More critically, these "fire watches" often consist merely of an hourly patrol through the areas involved, and are not continuous. Several points can be made relative to this factor: detection systems can be made more reliable, especially in the alarm or indicating circuitry, such that these fire watches are not necessary as frequently. Further, if a fire watch is not continuous, it is of limited value as a back-up to the detection system. If such a back-up is required, and this is not at all clear, the alternate methods for such a function should be investigated.

As was mentioned, it is necessary to differentiate between the reliability of various functional aspects of the detection system and to determine faults which are not detectable. The normal testing frequency for detectors is once every 4400 hours, as required in the plant Technical Specifications. These tests indicate the operation of several functions.

1. response to a given source strength

2. integrity of alarm circuits

3. integrity of trouble circuits

It would be possible, by accumulating this test data, to estimate the failure probabilities of a detector system without further analysis. . The trouble circuits or supervisory aspects of a detection system provide continuous monitoring of some system faults. Specifically, power source availablility and circuit integrity are monitored. It may be necessary, however, to detail any failure modes which may result in undetected failures. 
2. False and Spurious Alarms

Adequate data exists on the causes of spurious or false alarms in residential and commercial type occupancies. Such data exists for nuclear power plants in the form of incident and outage reports. False or spurious alarms tend to be concentrated in certain plant areas. They are oftell a result of envirnnmental variables on the detector sensitivity. The impact of, for example, high ventilation into an ionization type smoke detector has been discussed. Additional problems in nuclear power. plants include: dirt and dust accumulations, steam leaks, smóke frum welding, cutting, etc.

The National Bureau of Standards, in a study of health care facilities (14), indicates an overall false alarm rate of $4.4 \times 10^{-2}$ faíse alarms per device per year in service. This study also indicated no difference between photoelectric and Ionization type detectors with respect to false alarm rates. A Japarese study (50) indicates that the percentage of the false alarms in all occupancies due to environmental factors is approximately 67 percent. These factors include those most often associated with false alarms in industrial facilities.

Because most false and spurious alarms are a product of poor system design these problems in nuclear power plants can be virtually eliminated by proper design. 
3. Quantitative Reliability Analysis

Fire detection systems are expected to have a failure probability on the order of $10^{-1} /$ demand (15). This is an upper bound for most systems. Alvarez and Hasegawa (16) have performed fault tree analyses of detection systems using the IMPORTANCE computer code. They identify the indicating circuitry as a major source of failures. These circuits are the source of single port failure events. This analysis has shown that standard existing reliability analysis methodologies:can be utilized to effectively evaluate fire detection systems. This relatively high failure rate probably does not result in significant loss to plant safety. If so, then the reliability analysis may be defeated.

It is clear that sufficiently well developed techniques exist for quantifying the reliability of any particular hardware item or function. of a detection system. The techniques of fault tree analysis, failure modes and effects analysis $(17,18,19,20)$ as well as other methodologies can be applied to detection system reliability analysis.

There has been some recent work on the specific problem of predicting smoke detector reliability $(21,22,23)$. Standard methods for evaluation were found to be underestimating failure rate compared to observed generic failure rates (21). Further, the author reports that continuous changes in the prediction techniques for smoke detectors will be required. He bases this argument on the evolution of certain military standards. A 
procedure is then developed specifically for smoke detectors, including a major reported difference of the incorporation of "environmental stress factors." This leads to a speciailized dedicated procedure for the evaluation of detectors. Included is a very excellent review of data sources and validity and a complete description of the proposed procedure. The author also adequately addresses the problems with the reliability specifications in UL217 (24), basically referencing a military standard and presenting a minimum failure rate requirement. Conceivahiy, UL217 will be revised to incorporate changes to the prediction methodology. These same comments apply equally to non-residential applications covered by UL268. This reference also indicates that significant problems exist with the use of manufacturers' failure rate data, citing several discrepancies. The magnitude of this problem is unknown. It appears, however, that adequate generic failure rate information will be available from manufacturers for a given device.

The methodology outlined for smoke detectors could also be applied to associated circuits, alarm panels, audible devices, etc. No standard failure rates can be readily obtained for the wide variety of existing plant detection systems. Therefore, each system would require analysis, if a numerical assessment of reliability was to be required. This approach would be of questionable value without first establishing an acceptable value. 
Failure on demand type calculations for intermittently used system functions will require more sophisticated reliability analysis techniques (18). The generic failure data could be utilized to approximate failure on demand probabilities, however, the error involved is unknown.

It is possible, with existing data, to predict the failure probability of any hardware item in a fire detection system. It is our opinion that, given sufficient need, these failure rates can be accurately specified.

A more difficult problem is the analysis of the detection of a randomdistribution of source strengths at the detector sensing location. A more detailed discussion on the nature of "source strengths" as it relates to detector response is given in Section III $B$. The problem is that it is expected that the sensitivity of the detection device will be a randomly distributed variable. This, therefore, requires determination or estimation of the response paramcters and their distributions. For example, the response signal of ionization smoke detectors is proportional to the product particle size and the number density of that size particle ( 25 ). However, for any given detector, the threshold alarm signal will vary with the source strength, power . level, detector "cleanliness," detector housing change and other parameters. It may be that a discrete number can be assumed for the signal response, thereby negating the need for this type of analysis. Even given the 
requirement, it is expected that the failure probability could be adequately estimated; it merely adds complexity to the problem.

This issue brings up a more important, broader issue. Given the stochastic nature of fires, particularly the fire signatures to be detected, the use of probability modeling for the entire detection system effectiveness may be required. The parameters of the necessary distributions could be estimated by examining the physfcal ndture of the detection system, fire and smoke plume development, and the response then calculated. This obviously enables one to account for the uncertainties that have been mentioned throughout this report. Watts (26) has reported on precisely this topic. This work has shown the great potential value of probabilistic modeling of physical fire phenomena.

\section{B. Detector Response}

We have separated the problem of evaluating the response of fire detection devices into two physically separate categories. One is the response of the detector to a given source term immediately adjacent to the detector housing. The other concerns the transport of the fire signature to the detector housing. Therefore, throughout this discussion these two sets of phenomena will be treated separately. In this section, heat and smoke detectors are treated separately. A brief discussion of smoke properties is also presented in this section. General information on detection system design with respect to detector response can be found in references 7,12 , and 15 . 


\section{Heat Detectors}

There are basically three variables which must be known to predict the response of a fixed temperature heat detector: (1) the temperature of the flow field; (2) velocity of the flow field adjacent to the detector; and (3) the "time constant" of the detector. Descriptions of the temperature and velocity fields are given in the section on bouyant plumes. The time constant arises from considering only the convective field around an element and relating this heat input to the heat capacity of the element. The time constant is then a measure of the sensitivity of a detector element. The time constant is essentially the ratio between the heat capacity of the element to the rate of convective heat transfer to the element. It is related to the temperature rise of the detector as follows:

$$
\frac{d T_{D}}{d t}=\frac{1}{\tau}\left(T_{F}-T_{D}\right)
$$

where:

$$
\begin{aligned}
& T_{D}=\text { difference between ambient and detector temperature } \\
& T_{F}=\text { difference between ambient and fluid temperature } \\
& \tau=\text { time constant }=M C_{P} / \mathrm{hA} \\
& M=\text { detector element mass } \\
& C_{P}=\text { detector element heat capacity } \\
& h_{1}=\text { convective heat transfer coefficient. to the element } \\
& A=\text { Surface area of detector element. }
\end{aligned}
$$


For a given $T_{F}$, the time when the detector element reaches activation temperature $T_{D}$ is directly given if $\underline{q}$ is known. Since $\underline{\tau}$ varies with the convective heat transfer coefficient, it is a function of the fluid velocity. The time constant can be estimated for a given element and configuration. Alternatively, a standard method of test has been proposed to determine the value of the time constant for an automatic sprinkler element's standard reference velocity. Thus, a standard time constant, $\mathcal{C}_{\text {, will }}$ we determined. The following relationship between a tested "standard" time constant and its variation with velocity has been widely used $(27,28)$ :

$$
\tau=\tau_{p}\left(V_{0} / V\right)^{1 / 2}
$$

$\tau_{0}=$ time constant at reference velocity

$V_{0}=$ reference velocity

$\tau=$ time constant at velocity $V$

This relationship is derived from the fact that the convective heat transfer coefficient is proportional to the square root of the velocity, and is a consequence of basic convective heat transfer considerations.

For rate-of-rise thermal detectors, another detector parameter is required: the minimum temperature rise that will result in an actuation. Values of $15-25^{\circ} \mathrm{F} / \mathrm{min}$. are the expected range of these figures. This aspect of the detector actuation would also have a time lag associated with it and could be easily obtained through testing. 
For heat detectors, however, it may be expected that the thermal lag is very minimal and hence corrections for this term may be neglected. A prief analysis of available heat detectors would determine the validity of this simplification. If time constant corrections are required, they could be readily made.

\section{Smoke Detectors}

Ionization

Several models have been proposed for the prediction of the actuation of ionization type detectors. Bukowski (25) examines these methods and describes the salient features of ionization type detector response. In this review of the engineering problems of smoke detector design, the following major variables: affecting the response of an ionization detector are listed:

\section{Ionization Detectors}

Particle Size and concentrations

Air velocity (velocity of aerosol entering chamber)

high

low

Chamber design

source of strength

electrode spacing

electrode bias voltage

shell design

detector enclosure design 
From a detector system design evaluation standpoint, the aspects of particle size and air velocity are major variables. The sensitivity (S) of an ionization detector in terms of relative chamber signal is directly proportional to $\mathrm{Ndp}$ where:

$$
\begin{aligned}
S & =I / I_{0} \\
N & =\text { number of particles } \\
d p & =\text { particle dlameler } \\
I_{O_{0}} & =\text { reference chamber current } \\
I & =\text { current }
\end{aligned}
$$

Bukowski points out that this distribution of particle size changes with time and space. In addition, the effects of coagulation of aerosols are often important.

High air velocity through the chamber will tend to increase sensitivity as ions will be evacuated from the chamber. With this high velocity, the concentration of smoke particles detected will be lower. It is a fairly easy matter to correct for high ambient air velocity in the design of the detectors. Litton (29) gives the following limits for air velocity through an ionization detector:

$$
Z P E<V<U E^{7}
$$

where:

$$
\begin{aligned}
Z P & =\text { Mobility of ion } \\
E & =\text { average electric field } \\
U & =\text { ion mobility } \\
V & =\text { air velocity through chamber }
\end{aligned}
$$


For smoke entering the chamber at low velocities, the response of the detector is expected to require a higher concentration of particles. Entrance velocity is one of the reasons for delayed response of detectors in fires.

Litton $(29,30)$ has fully developed a theoretical explanation of ionization detector response, hence detailed evaluation of the detector response is possible. However, the prediction of the environment in terms of particle size distribution and velocity through the sensing chamber remain, at best, only empirically determinable. It is clear that if particle size and velocity distributions are known, and sufficient information is available on the penetration of particles to the sensing chamber, the detector response can be predicted. The fundamental problem still remains, however, that there is no current method for predicting the particle size distributions in time and space for a given fire, even under simple ceiling geometries'. A brief discussion of data on smoke properties follows this section. It will be shown that the response of these detectors can be related by the characteristic length, $L$, and the DMR number (14), but this is of little current application to the theoretical prediction of smoke detector response.

\section{Photoelectric Detectors (light scattering type)}

Bukowski also reviews photoelectric smoke detector design. He lists the following major variables affecting the response of light scattering detectors: 


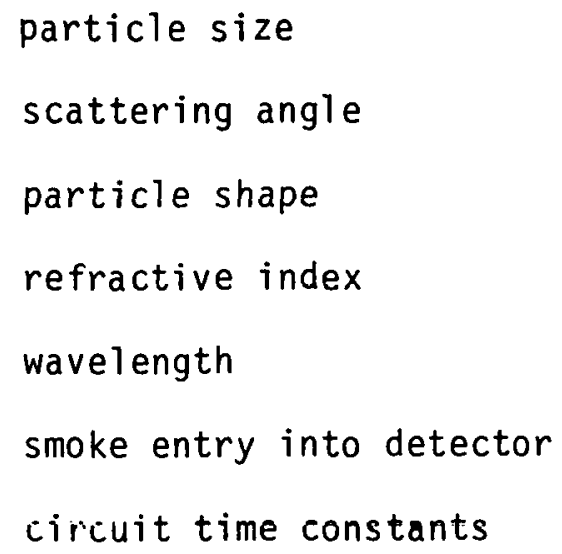

The major areas of uncertainty in predicting photoelectric scattering type detectors is the definition of the particle size distribution, particle shape and scattering angle. These parameters are discussed below under "Smoke Properties."

The effects of particle size distribution, scattering angle and particle shape are difficult to treat independently. Light scattering theories treat particle sizes in ranges based on the particle parameters, $\alpha$ which is defined by $\underline{\alpha}=\frac{\pi u p}{\lambda}$. These ranges are normally expressed as shown below:

TABLE 1

$\begin{array}{lll} & \text { General } & \text { Bukowski } \\ \text { Rayleigh region } & \alpha<<1 & d p<\lambda \\ \text { Mie region } & \alpha \approx 1 & 1 \lambda<d p<4 \lambda \\ \text { Bricard region } & \alpha>>1 & d p>4 \lambda\end{array}$


It is reported that in the Rayleigh region, the output signal is proportioned to the 6 th power of the particle diameter. In the Mie region the signal varies with the 6 th to the 2 nd power of the particle diameter as one moves toward the limit of $4 \underline{\lambda}$. Above a particle diameter of $4 \underline{\lambda}$ the signal is proportional to the 6 th power of the particle diameter (25).

The selection of a scattering angle for maximum intensity of output should be based on refractive index, particle size and shape. Effects of particle shape remains the single largest source of uncertainty in the prediction of the response of these detectors. Zerull (31) indicates that the assumption of spherical particle shapes can result in significant error. The effect of particle shape is further discussed below.

\section{Data on Smoke Properties}

A significant body of knowledge exists on the properties of smoke particulates developed from small scale tests. The data enables qualitative estimates of the size, type and distribution of smoke particles under flaming and non-flaming conditions. It is not within the scope of this report to review the status of smoke property research. However, because of its obvious importance in detector operation, it is briefly discussed below. A particularly useful review (32) gives smoke properties in terms of: fraction of weight loss to become particulate matter mass median diameter, Dmm standard deviation (log normal distribution assumed), $\underline{\tau}$ maximum optical density $\log \mathrm{I}_{0}$

$$
\overline{\mathrm{I}}
$$




$$
\begin{aligned}
& I_{0}=\text { source light intensity } \\
& I=\text { transmitted } 1 \text { ight intensity }
\end{aligned}
$$

volume/surface mean particle diameter, $D_{32}$

These data are given for a variety of heat rates, burning conditions (flaming, non-flaming), gas temperature, atmospheric composition, and ventilation rates as they apply to the test apparatus used. These are not full scale results, but should be considered as qualitative guides for detection system design. An interesting example for LWR plants is PVC. Results are given for 7 types of PVC with varying plasticizer and additive concentrations. A typical plot of smoke properties data is shown in Figure 2.

Under different heat rates, non-flaming fires, the mass median particle size $(D \mathrm{~mm})$ lies between $1.42 \mu \mathrm{m}\left(3.2 \mathrm{w} / \mathrm{cm}^{2}\right)$ and $1.2 \mu \mathrm{m}\left(3 \mathrm{w} / \mathrm{cm}^{2}\right)$. Comparisons between flaming and non-flaming conditions indicate a Dmm of .44 at a $2.5 \mathrm{w} / \mathrm{cm}^{2}$ heat rate for a flaming fire and Dmm of .73 for for a non-flaming sample at $6.2 \mathrm{w} / \mathrm{cm}^{2}$ in air. Bukowski (25) presented data which indicated that for $\mathrm{Dmm} \geq .3 \mu \mathrm{m}$, photoelectric detectors were more sensitive than ionization detectors at a Dmm of $1 \mu \mathrm{m}$ (Figure 3 ). . The difference in sensitivity is on the order of a factor of 60. Although this characteristic is well known, most LWR plants to date have relied on ionization type smoke detectors in such areas where the type of smoke particle will be similar to the PVC described above. This illustrates 


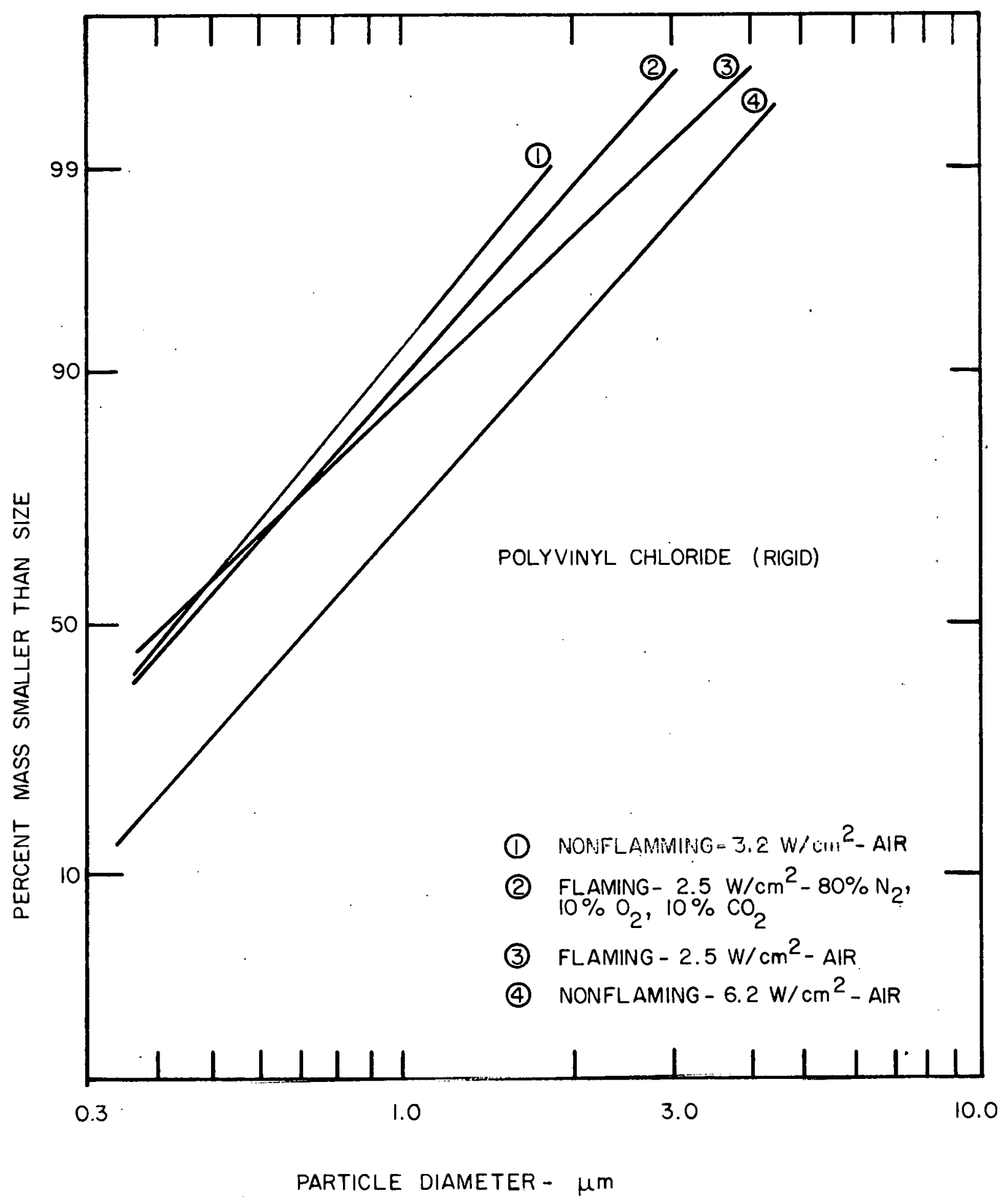

Figure 2: Smoke particle data, from (32) 


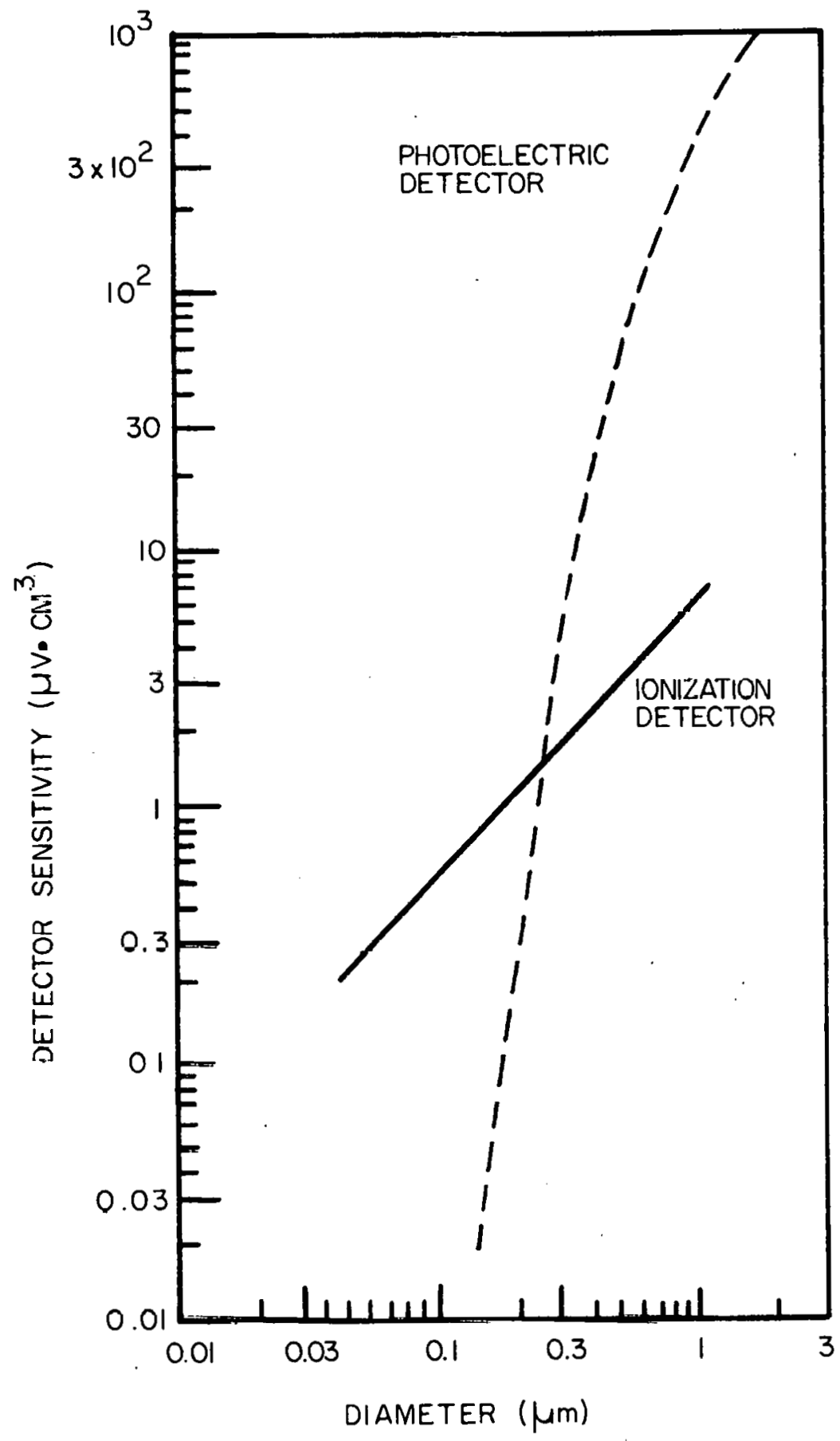

Figure 3: Detector Sensitivity vs. Particle Detection for Ionization and Photoelectric Detectors (25) 
the basic failure of designers to consider even qualitatively the basic nature of the fire and detection system that is used. This type of small scale data should be incorporated into șome form of design or evaluation guidance for design engineers, regulators, and those responsible for Quality Assurance, in order to determine more accurately the adequacy of a given detector installation. Moreover, these systems should be tested in fule scale facilities to determine the effect of these apparent design errors.

The above discussions have emphasized the importance of particle size, shape and concentration on detector response. To apply the data reported, the physical realities of the test methods must be understood. Particle size as expressed by mass median diameter, Dmm, is normally measured by using impactors (32). The values normally reported by this method. are "aerodynamic diameters" for a particle with a density of $1.0 \mathrm{gm} / \mathrm{cc}$. This means that the particle measured behaves like a spherical particle with a density of $1.0 \mathrm{gm} / \mathrm{cc}$ and diameter of Dmm. Particle size distribution described this way provides no information regarding the actual shape of the particles.

Sillce particle shapes play an important role in predicting light scattering, the limitalions of data from impactors must be appreciated. The effect of particle shape has been stated as a limitation in calculating light scattering in photoelectric detectors. To quantify the effects of particle shape, it is necessary to discuss the combined effects of particle 
size, shape and concentration $(33,34)$.

Few calculations have been made to develop data for non-spherical particles. For small particles $\alpha \ll 1$, in the Rayleigh (dipole) scattering range the shape of the particle has little effect on the scattering pattern for particles of equal volume. For $\alpha \approx 1$ which includes most smoke particles, the scattering pattern is determined by the angle between the incident beam and the long axis of the particle.

For particles cylindrical in shape, the smaller the difference between the length and diameter, the closer the scattering approximates that of spheres. The scattering pattern for non-spherical particles is similar to that of a sphere with an identical projected area. This is illustrated in Figure 4. This relationship applies best when the concentration of particles is great enough to ensure a random distribution of particle axis orientation with respect to incident light beams.

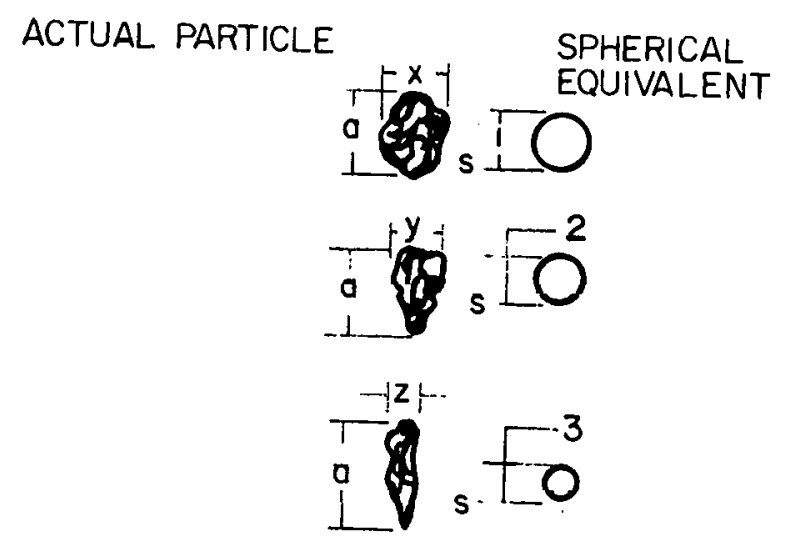

FIGURE 4 
Small scale smoke property data are also useful in developing criteria for the testing of smoke detectors. The response of a detector can be related to the particular hazard(s) involved. Standardization of particle size parameters will then allow some meaningful comparison of routine detector testing. However, small scale test data is required for Polyethylene, $X L P E$, and several other specific LWR fuel package types.

Bukowski shows the effects of smoke aging in terms of its effect on signal strength. He presents a sample calculation for which the concentration of smoke particles decreases by a factor of 2 in 14 minutes (25). This has the greatest potential impact on ionization and light attenuating type detectors.

A Japanese study (35) indicates the importance of smoke aging, coagulation, atmospheric composition, heat rate, ventilation, temperature and related parameters. These data illustrates the problems involved in estimating particle size, distribution, concentration, ctc., with respect to developing meaningful standard aerosols to which smoke detectors should be tested against. Again, however, this type of data would be useful in determining qualification environments and design guidance.

3. Buoyant Plume/Ceiling Jet Models

Considerable work has been conducted on quantifying the physical phenomenon of fire plumes and ceiling jets. Yokoi published the first and now classical work un this topic. More recent significant contributions have come from 
Alpert $(36,37)$, Zukowski, et al $(38,39)$, and Heskestead and Delichatsios (40) among others.

The problem which has been consistently studied is shown in Figure 5 . A buoyant plume develops above a heat source. It evolves to a fully turbulent plume entraining ambient air into the plume. When it strikes the ceiling, it forms a cuiling jet where air is also entrained. The ceiling jet then spreads across the underside of the ceiling, losing momentum to a viscous sublayer formed at the ceiling. The layer and plume cool through convection and through the entrainment of cold air.

It appears that for early fire growth situations typically of interest in detection system design, adequate models exist to predict the temperature and velocity fields. In cases where the descent of the smoke layer affects the plume and recirculation of smoke and combustion products occurs, adequate models are not available. For very weak heat sources such as smoldering fires, the impact of the environmental conditions is very strong and this situation is not as well defined.

For all plume modeling efforts, it is necessary to know the heat release rate to the plume, i.e., the convective heat release rale. Ubviously, the fuel geometry type, etc., will alter the radiative properties of the flame, and hence, it is nerescary to estimate the convective heat output of a given fuel bed. More work needs to be performed in this area, however, it appears that adequate estimates are currently available for the purposes 


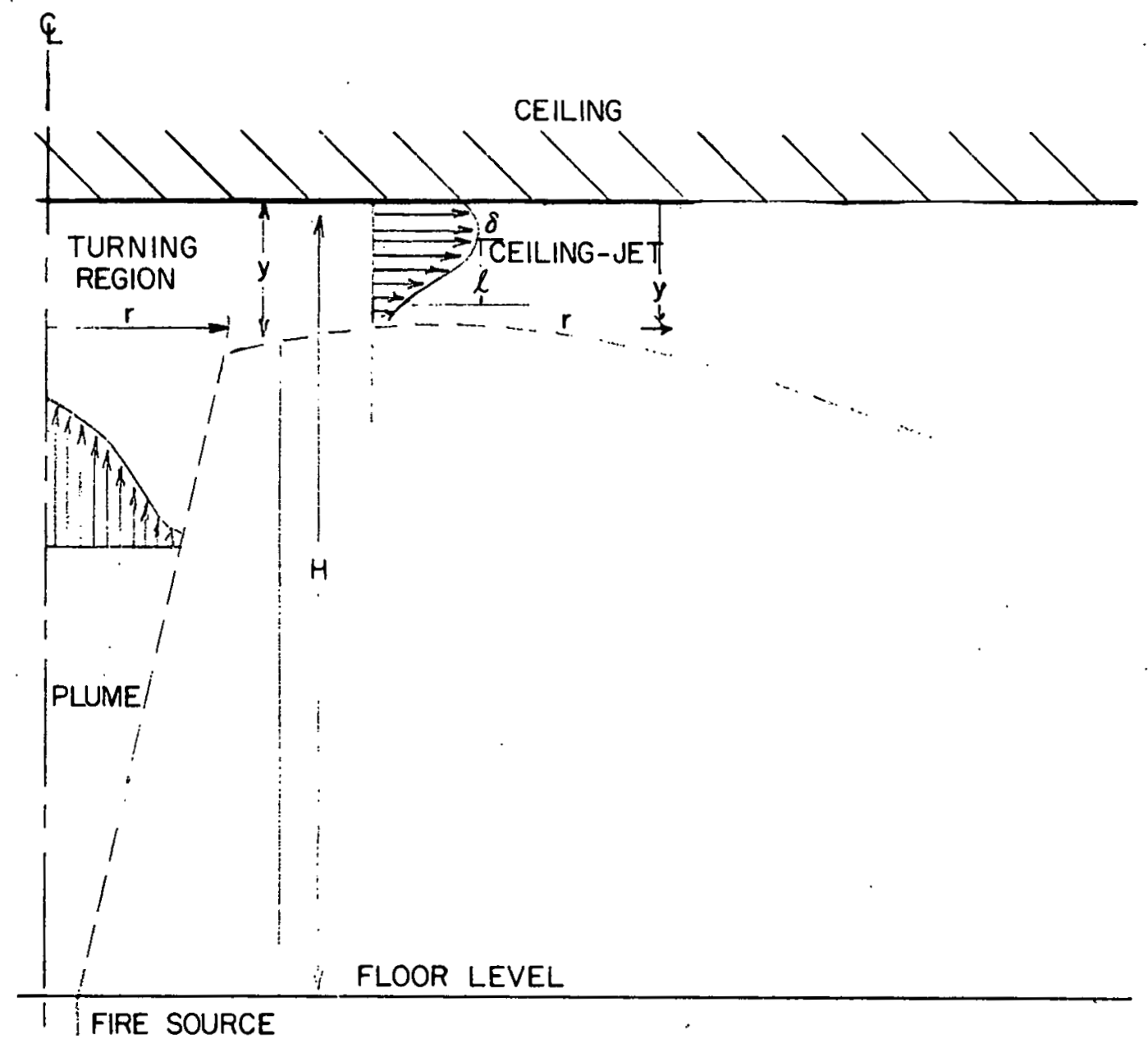

Figure 5: Buoyant Plume and Ceiling Jet Description (35) 
of detection system design and evaluation. Cooper (41) has estimated that 35 percent of the heat release of a fuel bed is lost to radiation from the flame; Beyler (28) assumes 30 percent.

The theoretical models have yielded very useful correlations for temperature and velocity distributions. Beyler has derived the following by computer experimentation based on Alpert:

Maximum velocity ( $p l$ ume)

$\ddot{r}<2: \quad V_{\max }=.422 r(-.711)_{Q} \cdot .333_{H^{-.33}}$

$\bar{r}>2: \quad V_{\max }=.363 r^{-.437} \mathrm{Q} \cdot .333_{H}-.33$

Maximum temperature ( 1 l ume)

$\overline{\mathbf{r}}<2: \quad T_{\max }=9.357 \mathrm{r} \cdot(-.633)_{H}(-1.667)_{\mathrm{Q}}(.667)$

$\bar{r}>2: \quad T_{\max }=8.551 r^{(-.478)_{H}}(-1.667)_{Q}(.667)$

Velocity in jet layer

$V=V_{\max } \exp \left(y_{1}-2 / 1^{2}\right)$

$y_{1}=y-8$

$T=T_{\max } \exp \left(y_{1} 2 / 7^{2}\right)$

Velocity in boundary layer, thickness

$V=V_{\max }(y / \delta)^{1 / 7}$

$T=T_{\max }(y / \delta)^{1 / 7}$ 


$$
\begin{aligned}
& \bar{r}=r / H \\
& r=\text { radius from fire axis, } m \\
& H=\text { virtual source ceiling height, } m \\
& \delta=\text { sublayer thickness, } m \\
& y=\text { distance of point from ceiling, m } \\
& Q=\text { heat release rate, } k w
\end{aligned}
$$

These dimensions and the basic structure of the plume model used for this work is shown in Figure 5.

Reference 39 gives the following correlations for the buoyant plume and ceiling jet temperature and velocity profiles. These expressions are used in Section $V$ to evaluate heat source strength parameters. For the buoyant plume:

$$
\begin{aligned}
& Q^{*} Q^{*}(z)=\frac{Q}{P_{\infty} C p T_{\infty} \sqrt{g z} z^{2}} \\
& \frac{\Delta T_{\max }}{T} \approx 9.11\left(Q^{*}(z)\right)^{2 / 3} \\
& \frac{V}{\sqrt{g z}}=3.87\left(Q^{*}(z)\right)^{1 / 3} \\
& b / z \approx .138
\end{aligned}
$$


For the ceiling jet:

$$
\begin{aligned}
& Q^{*}(H)=\frac{Q}{P_{\infty} C p \quad T_{\infty} \sqrt{g H} H^{2}} \\
& \frac{\Delta T \text { ad }}{T}=f_{1}\left[\begin{array}{lll}
r / H \quad Q^{*} & (H)
\end{array}\right]^{2 / 3} \\
& f_{1}(r / H)=\frac{T_{\max } / T}{\left(Q^{*}\right)^{2 / 3}}
\end{aligned}
$$

where:

$$
\begin{aligned}
Q & =\text { convective heat release rate } \\
\mathrm{p} & =\text { density }\left(\mathrm{kg} / \mathrm{m}^{3}\right) \\
\mathrm{CP} & =\text { specific heat }(\mathrm{Ws} / \mathrm{kg} \mathrm{K}) \\
T & =\text { ambient temperature }\left({ }^{\circ} \mathrm{C}\right) \\
\mathrm{g} & =\text { gravitational acceleration }\left(9.8 \mathrm{~m} / \mathrm{s}^{2}\right) \\
\Delta T_{\max } & =T_{\max }-T\left({ }^{0} \mathrm{C}\right) \\
V & =\text { velocity }(\mathrm{m} / \mathrm{s}) \\
H & =\text { ceiling height }(\mathrm{m}) \\
\Delta T a d & =T_{\max }-T\left({ }^{O} \mathrm{C}\right) \text { for adiabatic ceiling assumption }
\end{aligned}
$$

Heskestead and Delichatsios $(40,42)$ have successfully developed scaling laws for temperature rise and velocity distributions for unsteady state situations where the fire growth rate can be represented as a power law. These relationships will be very useful in defining environments of detectors of unobstructed ceiling cases. 
Another situation which has been examined is shown diagrammatically in Figure $6(38)$. The heat transfer coefficients, velocity and temperature profiles across the fluid reservoir are formed by the curtain walls. This is a similar problem to that studied by Heskestad and Deliachatsios (43, 44) for beam pocket geometries. This particular geometry applies for small compartments or in large compartments after a long time. In general, however, this situation is not readily modeled due to:

1. effect of recirculation of combustion products:

2. uncertainty in ventilation/fluid flow aspects;

3. effect of descendant smoke layer on plume behavior.

To date, the following situations have been successfully modeled:

1. prediction of the temperature and velocity profile; fields of a buoyant plume above a heat source of known convective heat release;

2. prediction of the behavior of the turning region and ceiling jet, subject to previously mentioned constraints;

3. prediction of the heat transfer coefficients to ceiling and wall surfaces;

4. prediction of the effects of curtain wall geometries.

In general, the following limitations apply to these methods:

1. the plume must be defined above the combustion zone. In small incipient fire situations, this is certainly not a major concern. Good experimental agreement can be obtained for low 


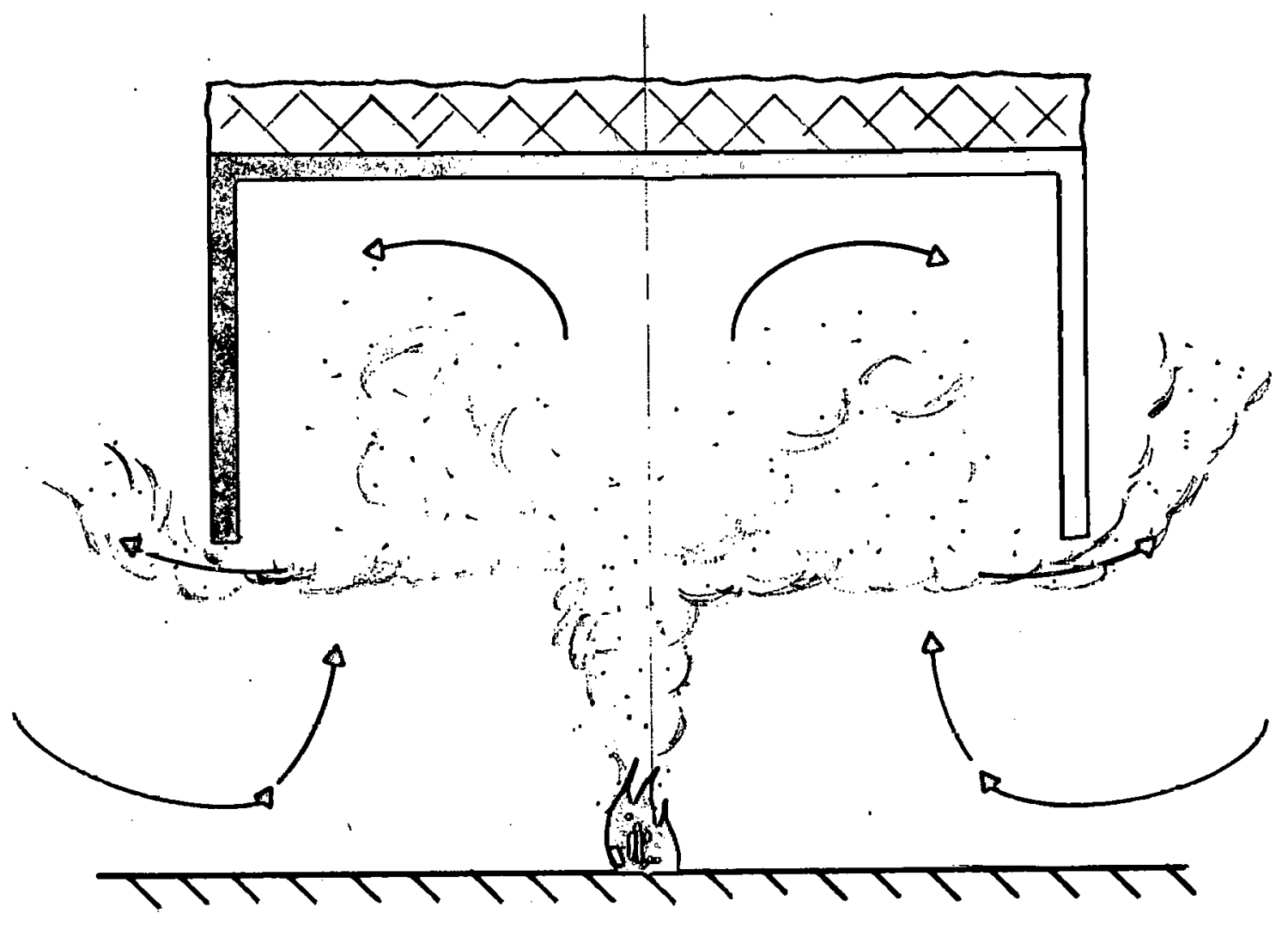

Fiqure 6: Effect of Curtain Wa11/Beam Obstructions (37) 
fuel bed level combustion zones. Reacting plumes and jets are not as clearly understood and additional work is required. However, sufficient understanding exists for the purposes of estimating detector response.

2. Obsturctions cannot be treated in a general fashion. In nuclear power plant facilities, a qualitative understanding of the impact of cable trays, beam pockets, piping racks, etc., must be obtained through tests. So we have a situation where given the heat release rate (convective) as a driving force, the temperature and velocity fields can be adequately predicted for smooth obstructed ceilings in both large and small compartments. The effects of recirculation, important in late fire development trees and smaller compartments, reacting ceiling jets, obstructed ceiling geometries, ambient stratification and ventilation rates have not been adequately examined. However, informaton from other sources on non-fire type plumes is sufficiently well developed to predict the behavior of "negative hunyant" plumes (where significant stratification of the environment at the ceiling exists.) Further relationships could be developed for predicting entrainment, dilution diffusion of fire plumes by ventilation systems, similar to existing work on turbulent jets (45).

These situations form a major class of existing installations which vary widely between facilities. An adequate prediction methodology could be partially based on available work, but significant effort would need to be expended. 
More important and far more difficult from the standpoint of current fire modeling is the prediction of smoke signature parameters in a plume-ceiling jet problem. To adequately predict the response of a products-of-combustion detector we have seen that the particle size distribution and velocity through the sensing chamber play a key role relative to response by the detector. This is the major current difficulty with any analytical approach to detection system design. However, the approximations given in the discussiun of semi-empirical methods provide a mechanism for estimating these parameters.

\section{Environmental Variables}

As stated above, the interaction of environmental variables has a great effect on the response of detectors. In some cases, these variables will govern the transport of the smoke. At the very least, these variables. complicate theoretical modeling of the smoke movement to the detector. Because of these factors, the evaluation of fire detection system effectiveness in LWR facilities is a significant unresolved problem. These variables will also alter the smoke characteristics such as particle size distribution, although this is a less significant problem than the effects on smoke transport. This section discusses the fulluwing environmental variables:

- Temperature Stratification

- Ventilation

- Obstructions

- Room Geometry 


\section{Temperature Stratification}

If a plume is sufficiently weak, such that the density of the plume is greater than the ambient density along a vertical profile, the plume will cease to rise and will stratify along lines of equal density, before reaching the ceiling and, conceivably, the detector. This phenomena is illustrated in Figure 7. This is a substantial problem in certain LWR areas with high ceiling heights and/or limited ventilation, particularly when it is desired to detect fires very early in the smoldering or weak plume stage. This was described in references 42 and 43 and formed the basis for these authors neglecting smoldering type fires. Reference 45 gives a plot of plume height versus the Froude number for a variety of source strengths. The plot is quasi-linear against $(\mathrm{Fr})^{\frac{1}{2}} \mathrm{~d}_{j}$ (Figure 8) where $d_{j}$ is the jet diameter. Another plot gives the range of stratification $X_{L D}$ and $X_{m}$ for various values of a $p l u m e$ source strength (Figure 9). Indeed, the phenomenon is well known but has been little studied in the fire literature. Bukowski (47) performed studies on a mobile home environment under varying vertical temperature distributions. His conclusions were that :

1. the vertical temperature inversions were significant to the detector response

2. the response to weak smoldering fires is a function of the . "movelierill of smoke."

However, the vertical temperature gradients were weak and ceiling heights less than normally cncountered in LWR facllities. Tests are required to 


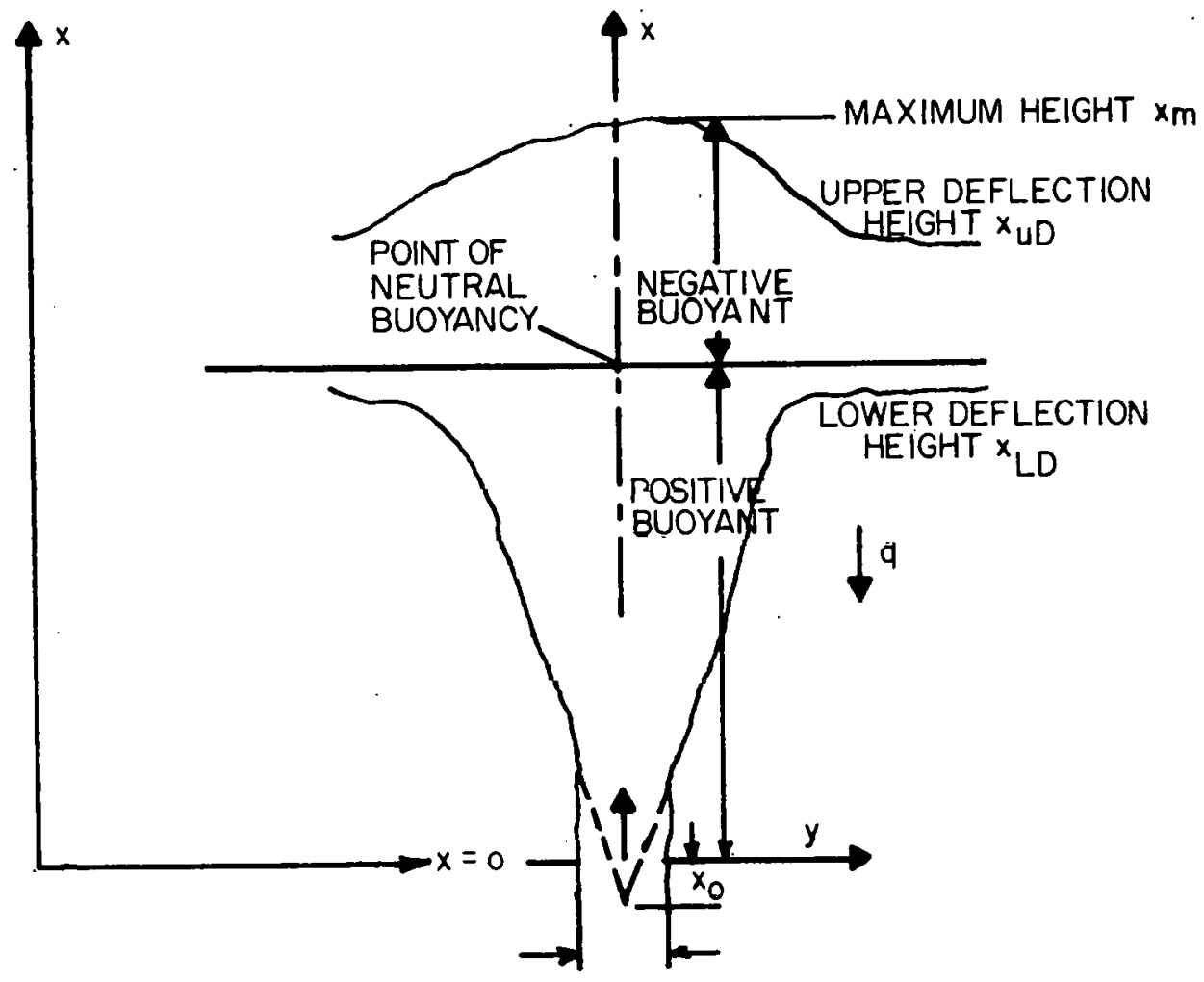

Figure 7:" Neyalive Buoyant Jet (14) 


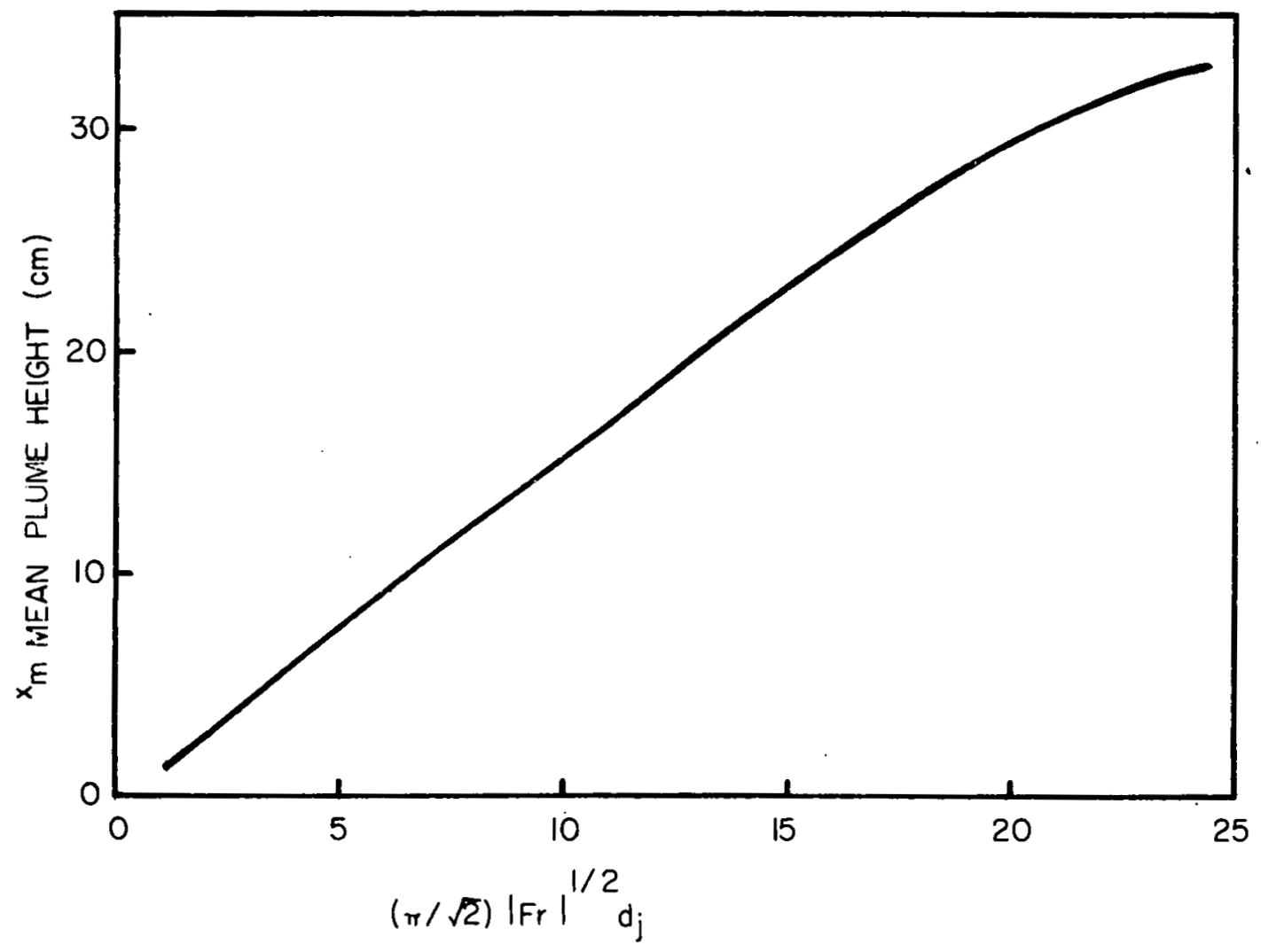

Figure 8: Maximum Plume Rise for Negative Buoyant Jet (44) a. 


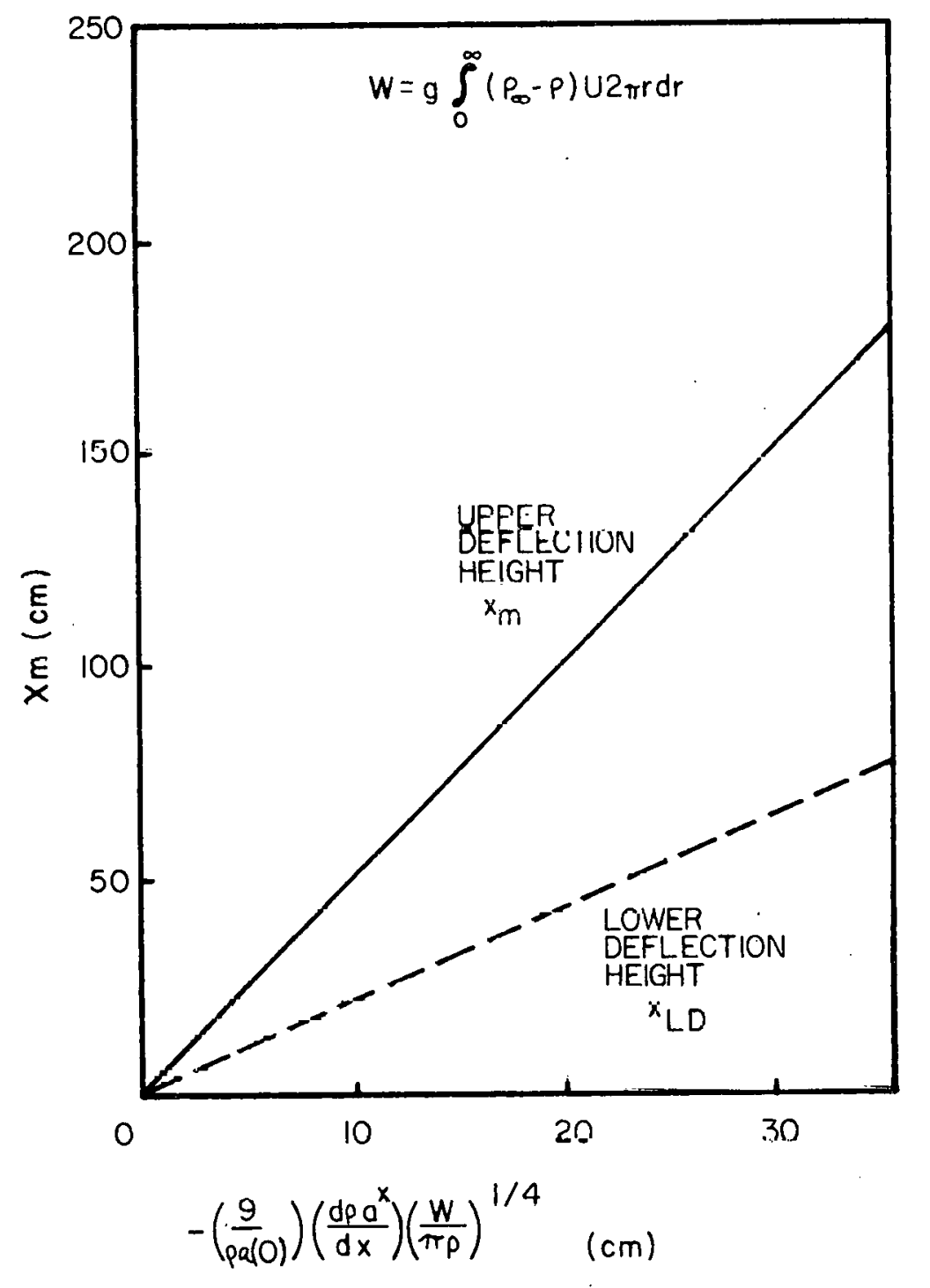

Figure 0: Stratification Limits for Negatively Buoyant Plume (44)

50 
measure the effect of these temperature profiles in full scale facilities with varying plume heat release source strengths.

\section{Ventilation}

The effects of ventilation on the performance of detection sytems are divided into three basic categories: (1) plume distortion, (2) dilution, and (3) detector sensitivity. The effects of forced air movement on plumes have not been well defined for use in detector system design or evaluation. Some basic principles can be applied, however, regarding the location of detectors with respect to air supply and exhaust registers. Figures 10 and 11 display the effects of duct velocity on air discharge or inlets. Ventilation system design guidance (48) indicates that supply air jets have more far reaching effects than exhaust intakes. For these reasons NFPA \#72-1978 advises, "detectors shall not be located where air from supply diffusers could dilute smoke before it reaches the detectors." The most dramatic effect of such air supplies is not just dilution but rather a total distortion of a quiescent plume.

In the case of weak plumes, dilution of entire areas by large air flows can create delays in detector response. Specific guidance is contained in NFPA \#72-1978 for smoke detector placement in data processing facilities relating to the effects of dilution ventilation. Figure 12 , extracted from Appendix $A$ to the Standard, advises reduced spacing for large air change rates. Factory Mutual (10) also recommends reduced coverage 


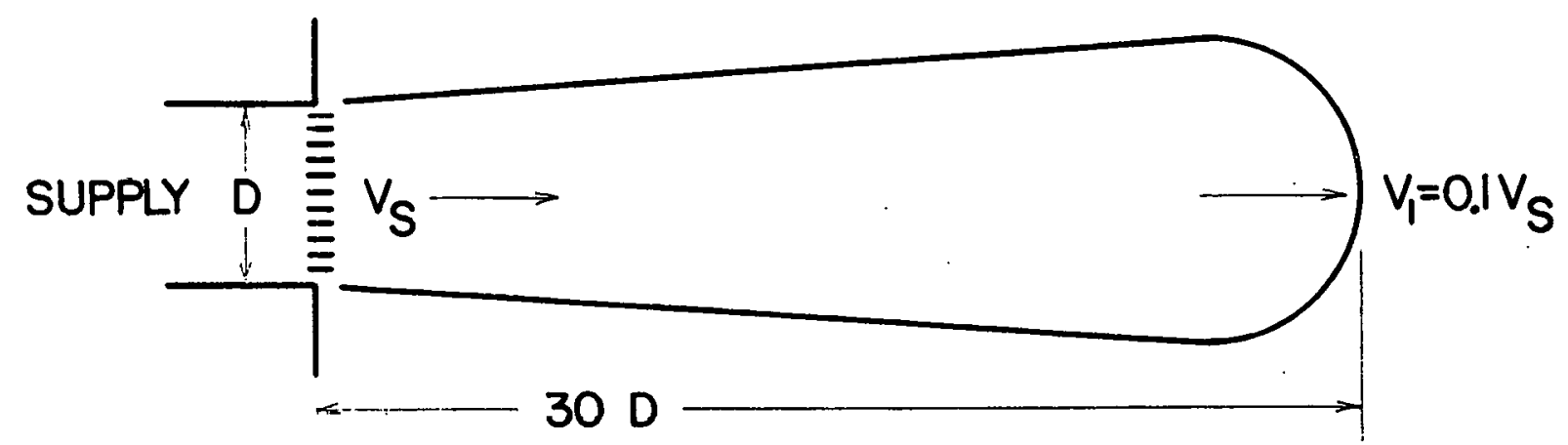

Figure 10: Supply Duct Velocity Profile

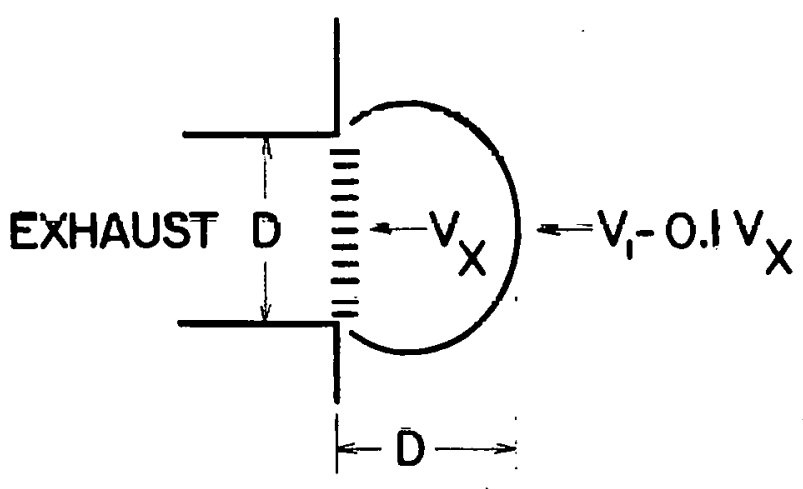

Figure 11: Exhaust Duct Velocity Profile

52 


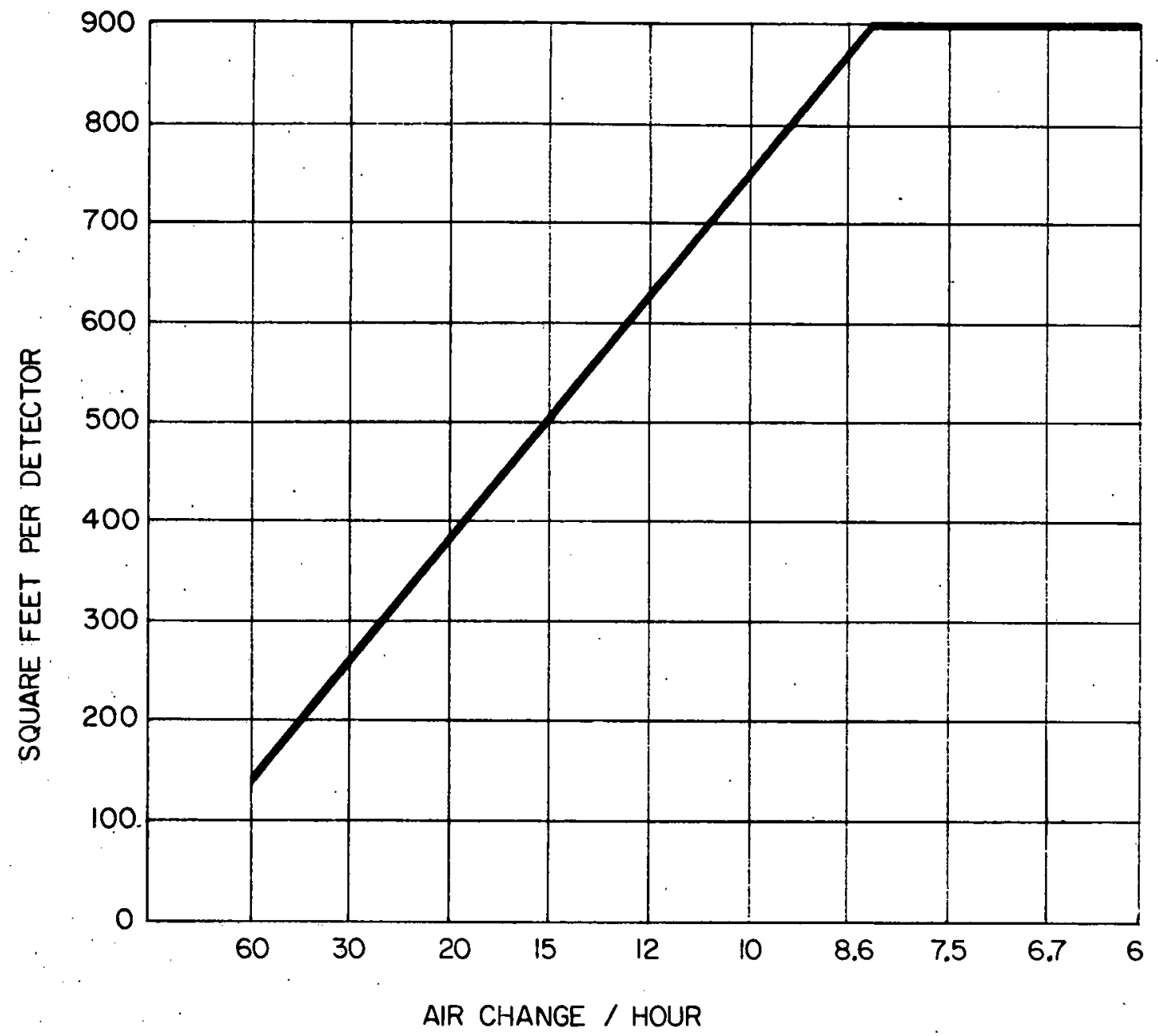

Figure 12: Area limits per detector versus ventilator rate from Appendix A, NFPA 72E 
area per detector (maximum of 200 square feet) for high air change rates (100 ft/min or 20 air changes per hour). Both references are based on judgment rather than extensive testing. Dilution ventilation will have a greater effect on low heat release, smoldering fires which will not produce pronounced plumes.

The third effect of ventilation is closely akin to the air supply velocity problems. Normal room type smoke detectors can be affected by high velocity air flow across the detector. One effect on ionization type particles-of-combustion detectors is to reduce the current flow between electrodes in the ionization chamber. Such a reduction caused by evacuating ionized air prior to its deposition on the electrode increases the sensitivity, as outlined in the section on detector sensitivity. This increase could cause greater frequency of false. alarm. It is unlikely, however, that this increased sensitivity would help mitigate the plume distortion or dilution problems referenced above.

\section{Obstructions}

The importance of obstructions such as beams have been examined $(43,44)$. However, no specific data is available on how obstructions such as beams, cable trays, piping/conduit racks, etc., impact smoke transport. Fuchs (49), in a classic work on aerosols, has identified these uncertainties. Deposition of particles from turbulent eddies formed around obstacles may have significant impact on the particle size and distribution, 
reaching a detector located downstream of such obstacles.

The generalized effects of obstruction to the verticle flow of buoyant plumes or horizontal flow of ceiling jets from impinging plumes can best be identified by testing described below.

\section{Room Geometry}

Room geometry parameters, including ceiling height, volume, wall location, floor area shape, establish the important spatial relationships between the hazard to be detected, the item to be protected, and the detector. The effects of ceiling height have been discussed in detail under plumes and thermal stratification. The effects of walls, room volume, and room shape apply to mixing, diffusion, and dilution of smoke. Those aspects of smoke transport may function in addition to plumes or in place of plumes when they will dominate the transport mechanism.

Perhaps the most important aspect of room geometry is the evaluation of the spatial relationship between the fire source, the system or equipment to be protected, and the fire detector. These spatial relationships will be important in evaluating the size of the fire to be detected (prior to damaging equipment) and the feasibility of in-situ testing to replicate test fire.

\section{Combined Effects}

Environmental variables interact to complicate any analytical assessment 

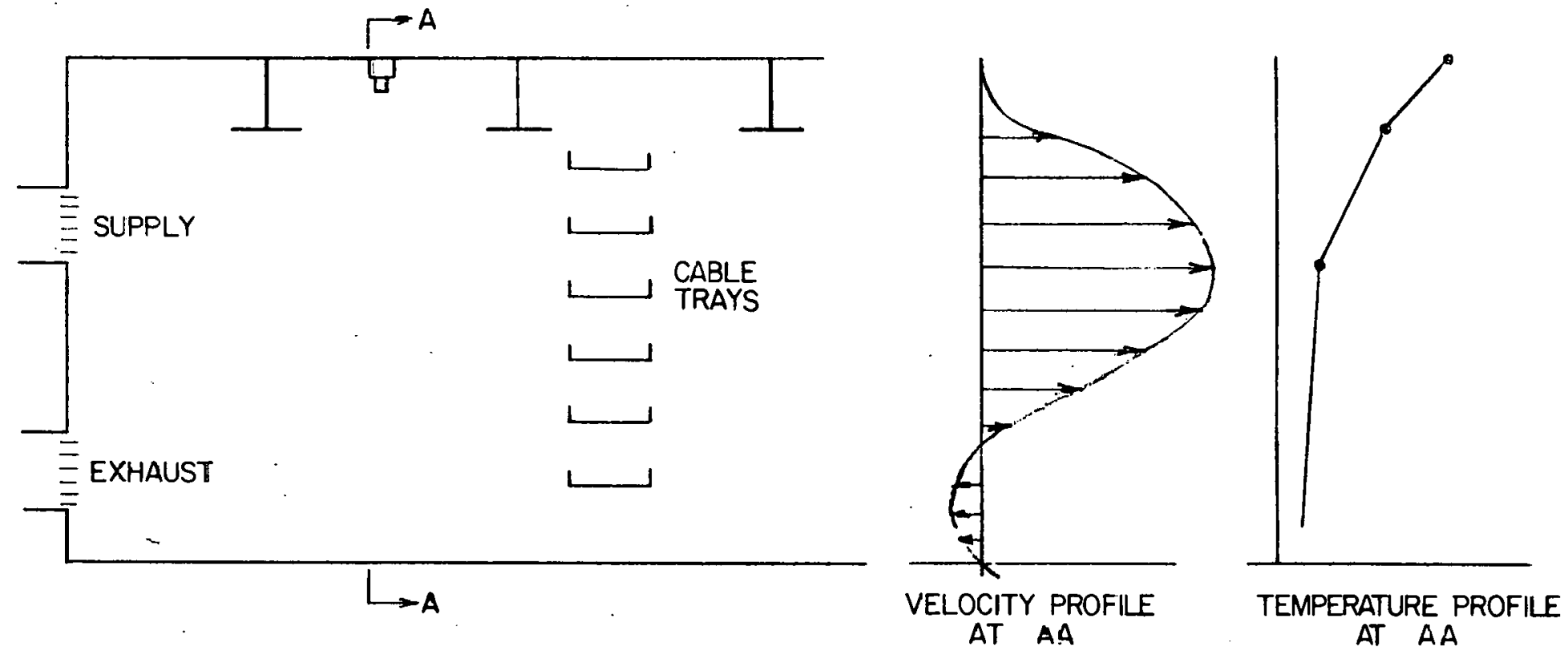

Figure 13

v

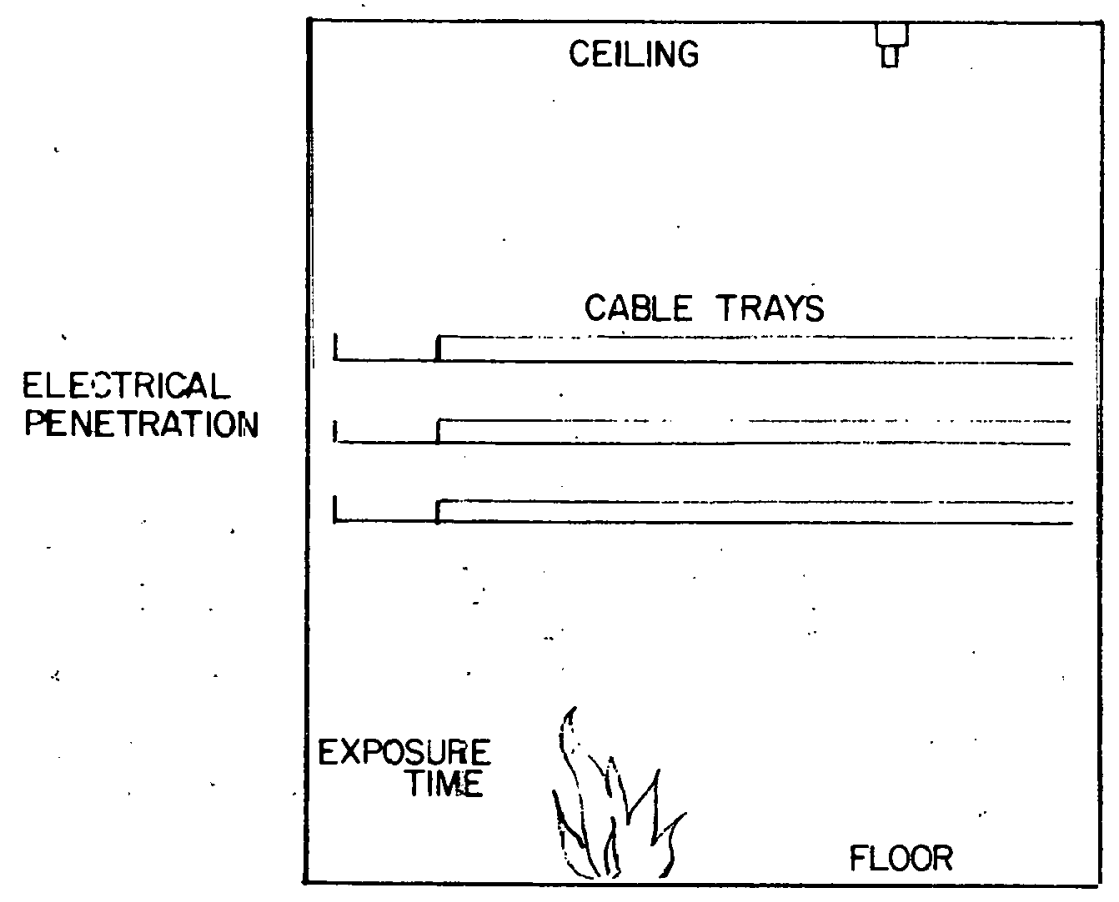

Figure 14 
of their effects. Because of this interaction, it is difficult to evaluate them independently. The LWR plant environments offer many examples of these problems. Figure 13 shows an example of a cable spreading room where ventilation, beam obstruction, and thermal stratification complicate the transport of smoke to installed ionization type particles of combustion detectors. 'Such environmental variables could delay, if not prevent, the actuation of the example detector.

A similar example is the containment area of an LWR plant where large air flow rates in recirculating coolers and high ceilings effect the response of detectors. As illustrated in Figure 14, these problems are further complicated by the spatial relationships between exposure hazard at floor level, cable trays at mid-roóm height and detection at the ceiling.

\section{Semi-Empirical Studies}

Heskestad and Delichatsios $(42,46)$ have successfully/correlated the listed spacing of:a UL detector for varying ceiling heights for different fire development growth times and heat release rates. The authors were able to adequately correlate the optical density of the combustion products to the local temperature rise. They report that the rate. of optical density to temperature rise does not vary áppreciably in time or space for the data they examined. Data from their tests indicate that this assumption is good for wood crib fires and valid for polyurethane fires up to a value of $r / H=4$. For cotton fabric fires, the fuel geometry 
and ignition mechanism appears to have significant impact in the specific optical density. For PVC fires, the concept of an "active.burning interval" is introduced to evaluate the ratio Du/dT. The authors give a table of representative values for the ratio Du/dT from several data sources:

Material

1. Wood

2. Cotton Fabric

3. Paper Waste Basket

4. Polyurethane Foam

5. Polyester Fiber

6. PVC insulation

7. Foam Rubber/Polyurethane

$$
\left.\underset{\left(\mathrm{ft}-10^{2} \mathrm{Ou} / \mathrm{d} J\right.}{-1}\right)
$$

.02

$.01 / .02$

.03

.4

.3

$.5 / 1.0$

1.3

This report gives further evidence of the problems of detecting smoldering fires in non-quiescent, temperature stratified environments. As expected for very "weak fires," the smoke plume horizontally stratified below the ceiling for extended periods of time (40-60 min.). For well heated $(1.3 \mathrm{kw})$ smoldering fuels, the smoke plume did not form an appreciable ceiling jet radially, extending only several feet. In their tests, a quiescent atmosphere existed, but temperature stratification wa's a signficant problem. The authors conclude that smoldering fires must be treated separately. Hence, the methodology applies only to the flaming fires. 
The authors report on the response of various types of detectors. They have presented a general method of calculating the response time of fixed temperature detectors to "power law" type fire development curves. As expected, good agreement is obtained. The response of rate-of-rise type heat detectors can also be predicted providing that the "rate-of-rise set value" is known (e.g., 15-250 F/min.).

The real problem lies with smoke detectors. The following equation was developed to predict the response of smoke detectors (ionization and photoelectric):

$$
D u_{r}=D u_{0}+L(d(D u) / d t) v^{-1}
$$

where:

$$
\begin{aligned}
& \text { Dur }=\text { value of Du at response } \\
& D u_{0}=\text { characteristic optical density of detector } \\
& L \quad=\text { characteristic length of detector } \\
& v \quad=\text { gas velocity }
\end{aligned}
$$

The characteristic optical density in this equation depends on the smoke, generic class of detectors, and detector sensitivity. L relates the "ease of entering" of the smoke into the detector. $L$ is independent of the smoke, and $L$ is specific for a given mode of detector. For photoelectric detectors, $L$ varies strongly with orientation $(L=87$ to $21 \mathrm{ft}$.) for the detector used in these tests.

The DMR parameter is expressed in another report. (14) as the Metertor 
Material Response number. This number indicates a temperature rise before detector activation for a given detector for a given material. Typical values given in reference are:

\begin{tabular}{lcc} 
Fire Type & Ionization & Photoelectric \\
\cline { 2 - 3 } Wood Cribs & 25 & 75 \\
Polyurethane Foam & 13 & 13 \\
PVC & 13 & 13
\end{tabular}

The basic concept is that the detector manufacturers will develop these DMR values for a particular detector.

The combination of the DMR and $L$ values then are used to completely characterize the:

1. aerosol composition at the detector as a function of $T$ (local temperature difference)

2. the response of the detector to a given aerosol composition.

Given these values, it is possible to predict the spacing required to yield detector activation time equivalent to the acceleration time obtained in a UL listing test at ceiling heights and fire growth rates different than the UL test.

Equivalent spacing for heat detectors is then predicted for "fast" and "slow" fires in a fire growth time of 150 and 600 seconds, respectively. 
This parameter represents the time between the time the fire growth rate becomes geometric and the time that the heat release rate reaches 1000 Btu/sec.

The results of this analysis enable a designer to alter the spacing of a UL listed detector, depending on the following variables:

1. fire development rate (fast/slow)

2. heat release rate at detection (e.g. $100,500 \mathrm{Btu} / \mathrm{sec}$ )

3. ceiling height

If the UL spacing, L; and DMR parameters are more for smoke detectors and the actuation temperature and/or the minimum rate of rise setting is more for heat detectors, then the spacing required is given. Figure 15, compiled from reference 14, shows these curves for heat detectors. of 20 and 50 feet spacing for 100,500 , and $1000 \mathrm{Btu} / \mathrm{sec}$ heat release rates for "fast" and "slow" fire development times. In this case, the UL spacing is a relative measure of detector sensitivity and has dramatic effects on the required spacing, especially at low ceiling clearances. Figure 16, again compiled from reference 14, : shows results for. such detectors with various $L$ and DMR numbers, for a slow developing fire. Note that the characteristic length appears to have little effect on the spacing above a 10 -foot ceiling clearance. Figure 16 is similar to Figure 17, but is plotted for fast fires, the characteristic length of the detector has more impact than in the previous case. 


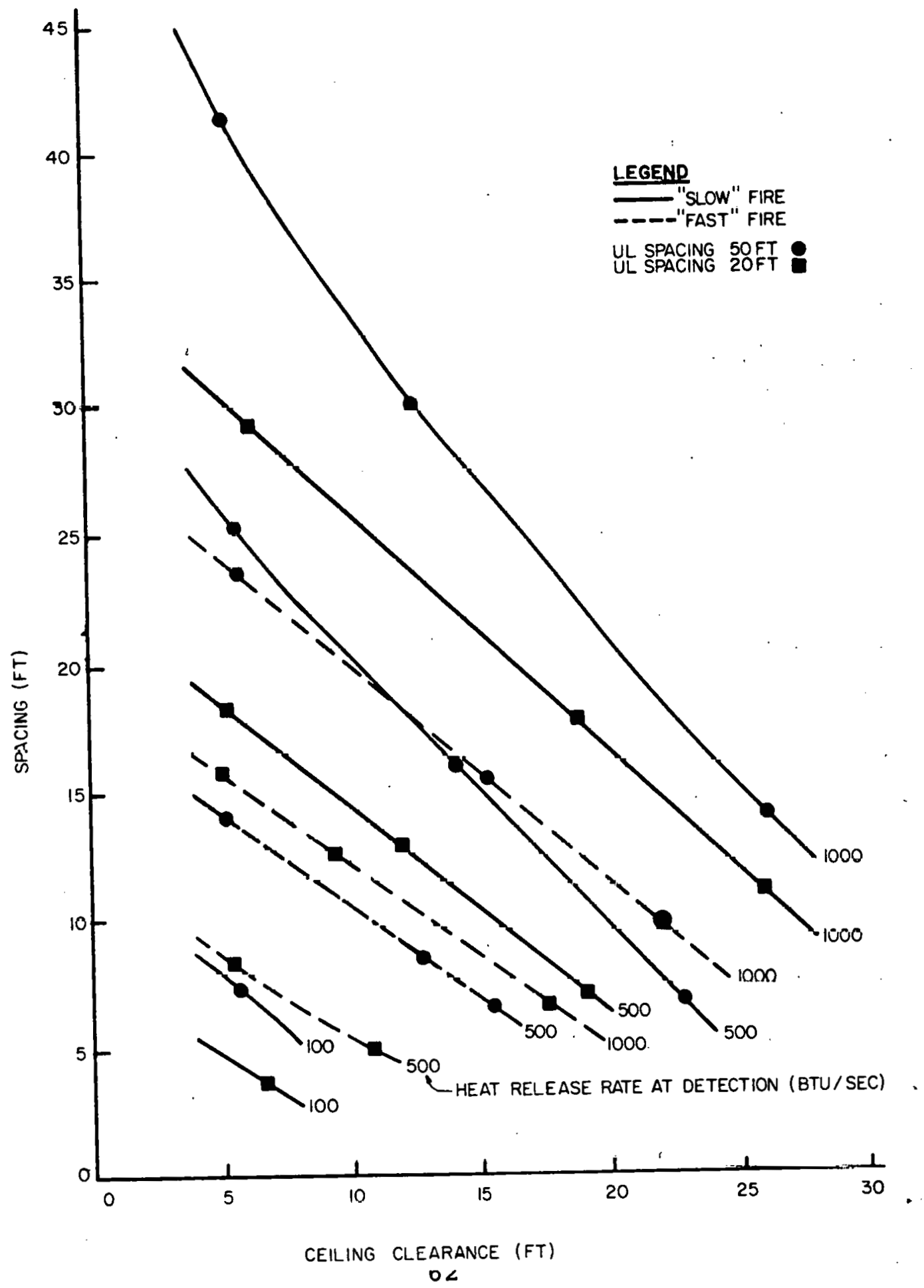

Figure 15: Heat Detector Response Curves (14) 


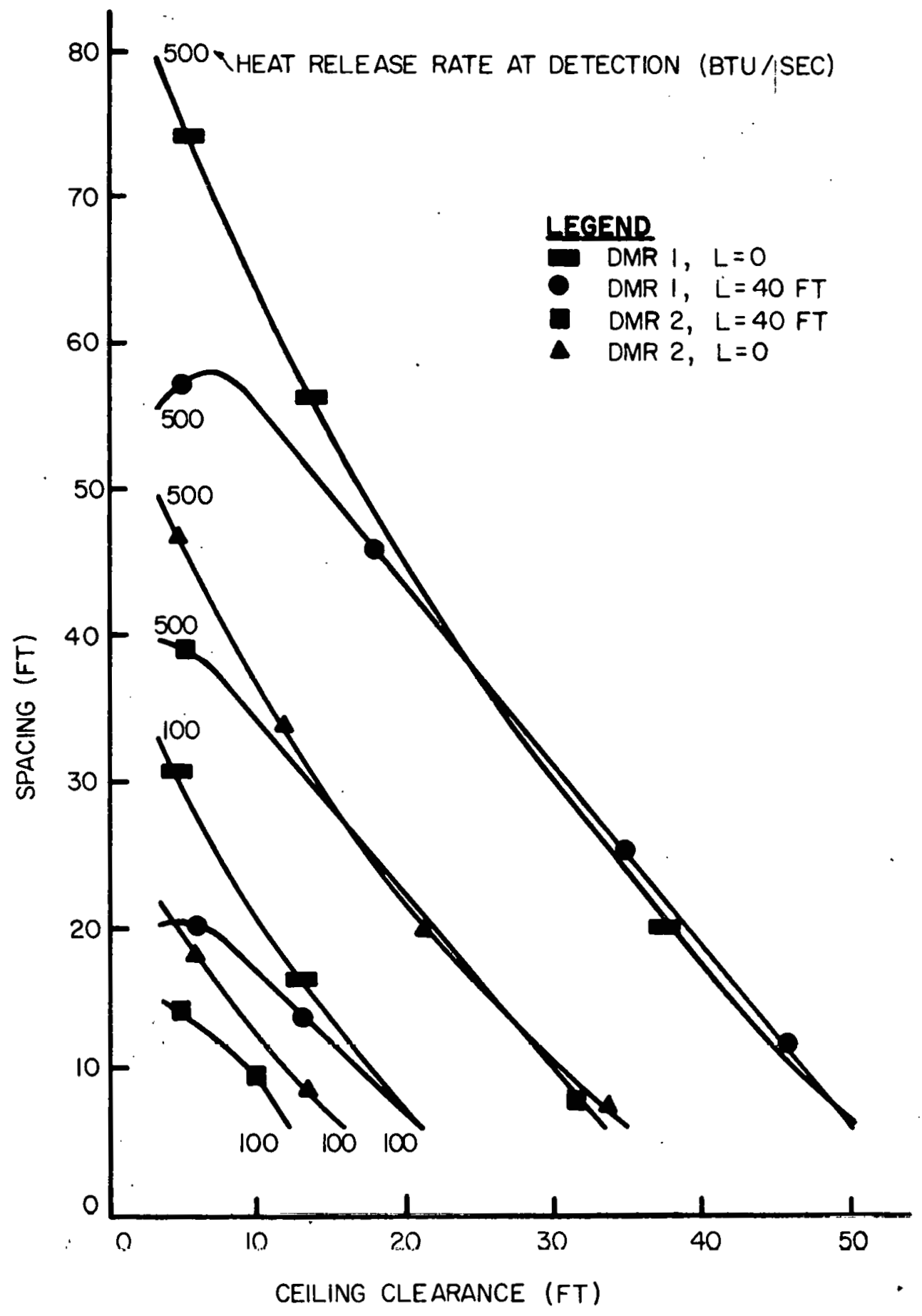

Figure 16: Smoke Detector Response Curves, "Slow" Developing Fire (14) 


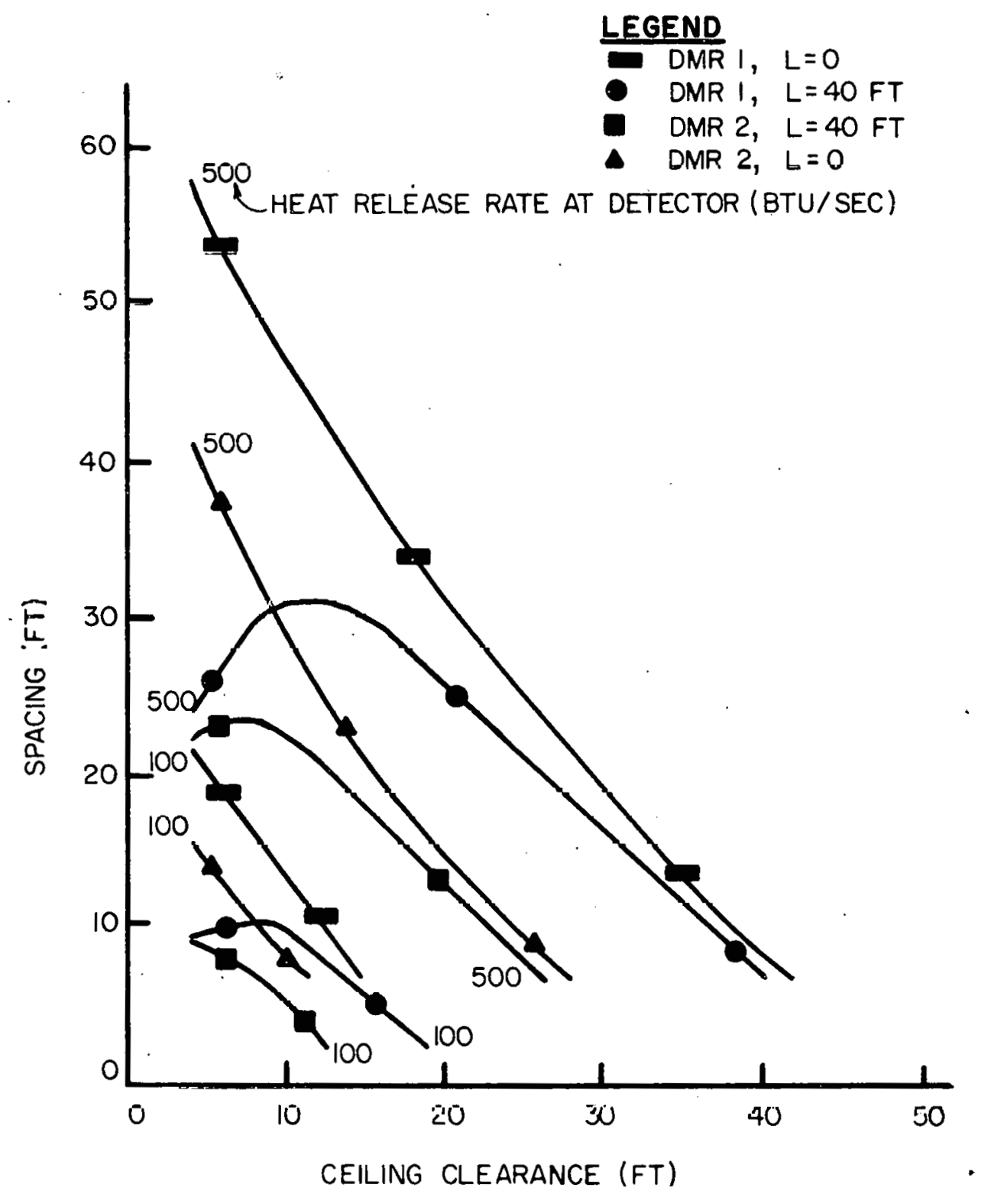

Figure 19: Smoke Detector Response Curves, "Fast" Dcveloping Fire (14) 
The methodology could be used for arbitrary test release rates and fire development times, provided that the fire growth rate can be adequately represented as a power law function of time, and for different values of the heat release rate desired to be detected. It is crucial to remember that these results do not apply to "smoldering" fire incidents, or obstructed thermally strafified, non-quiescent atmospheres.

The test program was extended to include ceilings with beam pocket type geometries. The maximum beam depth tested was 24". Again, based on experimental data for the temperature and velocity profiles at different locations in the beam pockets, the response of the detector was predicted. The results are subject to the same limitations as the unobstructed case with the additional limitations to certain beam depths and beam spacing geometries.

This work is very valuable in that it indicates that the very complex problem of ạernsol composition and detcctor response can be related to temperature, velocity, and two detector specific variables, $L$ and DMR. Further, it extends the great body of data on detector response available from standard UL test methods. Unfortunately, the analysis of smoldering type fires, highly stratified environments, non-quiescent environments and obstructed ceilings, is not available. These types of situations are very common in LWR plants and form the fundamental design environment in most cases. 
The method enables a designer to provide maximum area per detectors, at a given ceiling height, such that the fire will not exceed a certain size. In the case of the published analyses, this threshold size is $1000 \mathrm{Btu} / \mathrm{sec}$. This threshold size could be varied, depending upon the safety requirements of a given plant area. 


\section{PROPOSED IN-SITU TEST METHODS}

The particular environment in which a detector is installed will have significant effect on the responses of that system. The smoke/fire signatures from different combustibles and different fire conditions, in conjunction with the safety requirements in terms of the size of the fire at detection, should determine the design basis of the detection system. It has been shown above that, in general, this is not the case. Detection' system design in LWR plants is often lacking on even a qualitative phenomenological basis.

The problems of environmental variables form the key group of uncertainties in the prediction of detector response. An understanding of environmental effects is crucial to the meaningful evaluation of a detector system design. The variations between LWR facilities with respect to ventilation system arrangement, temperature stratification, obstructions, etc., precludes confident numerical treatment of all cases. An in-situ test method must he developed to permit adequate verification.

It has also been shown that at present the only tractable method of analyzing detection system response is to separate the detector response and the smoke and heat transport phenomena. This is especially usefut in developing an in-situ test methodology. The proposed test method involves the independent evaluation of two phenomena. Obviously, these are not physically discrete and independent phenomena. However, the 
advantages of such a treatment will become obvious in the discussion of proposed test methods.

\section{A. Evaluation of Detector Response Parameters}

The first part of the test problem, the evaluation of the detector response characteristics, can be performed utilizing polydisperse aerosol generators as per Bukowski (25) and Lee (11). This permits the quantitative evaluation of detector sensitivity for a specified design criteria. This replaces the "go/no go" evaluation often used. These tests would be conducted at the specified detector test interval, normally once every six months. The main advantage of using a variable polydisperse aerosol is the ability to replicate the smoke signature of the hazard located within the area. Particle size distributions could be specified for given hazards utilizing available small scale test data and subsequent confirmitory research. In this manner, the suitability of a detection device is tested against the specific hazard involved. Therefore, more reliable evaluation of the adequacy of the fire detection systems is possible.

There appears to be no major technical problems with this approach. Further, no additional testing demand is placed on the plant. Most importantly, the system can be more realistically evaluated.

B. Evaluation of Smoke/Heat Transport to the Detector

It has been shown that the major areas of uncertainty in detection system design are: 
1. Impact of environmental variables on smoke/heat transport to the detector. These environmental factors include:

- obstructions

- ventilation systems

- room or area geametries (ceiling height, location of hazard)

- thermal stratification

2. Aerosol compostion changes within the buoyant plume and ceiling jet.

Available plume models can adequately predict the temperature and velocity profiles for which good scaling relationships exist. This input can be used to develop a method for in-situ detector testing.

Several approaches to the techniques can be taken. This report develops several concepts which appear to be reasonable, given the physical nature of the phenomena and "real world" constraints on in-situ testing in LWR facilities.

1. Use of Small Heat Source to Simulate Plume

The simplest and most straightforward method to simulate a fire driven. plume is to utilize a small heat source as the driving mechanism. The most important variables to scale are convective heat release, temperature, velocity, and spatial variables such as layer thickness, plume dimensions, etc. As was discussed in the report, fire plumes have been successfully 
modeled and scaling relationships developed. Hence, the source term and expected plume variables can be estimated and compared to the results of in-situ tests.

In order to evaluate the range of heat source terms which may be required and the predicted temperature rise values which could be detecled, the correlations developed in reference were utilized to estimate maximum temperatures developed in the plume at various hat release rates and various elevations above the source. Figure 18 illustrates the results of this comparision. The figure also gives an idea of expected maximum temperatures in order to evaluate whether such a technique could be used in an operating plant where temperature increases must be limited. Similar relationships exist for ceiling jet temperatures, thus a minimum source term which will develop sensible temperature differentials can. be determined.

For example, if a $40^{\circ} \mathrm{C}$ environmental temperature is sufficiently low, then a sensible temperature difference of approximately $2^{\circ} \mathrm{C}$ exists at 3 meters above a $.5 \mathrm{kw}$ heat source. Another interesting aspect of these plots is the potential importance of ambient vertical thermal stratification. At 3 meters above a $15 \mathrm{kw}$ fire source, the temperature difference is approximately $5^{\circ} \mathrm{C}$. A $10^{\circ} \mathrm{C}$ difference between floor and ceiling is common in certain plant areas. One would expect that the plume above a $1.5 \mathrm{kw}$ would stop rising at the location of this temperature difference. 


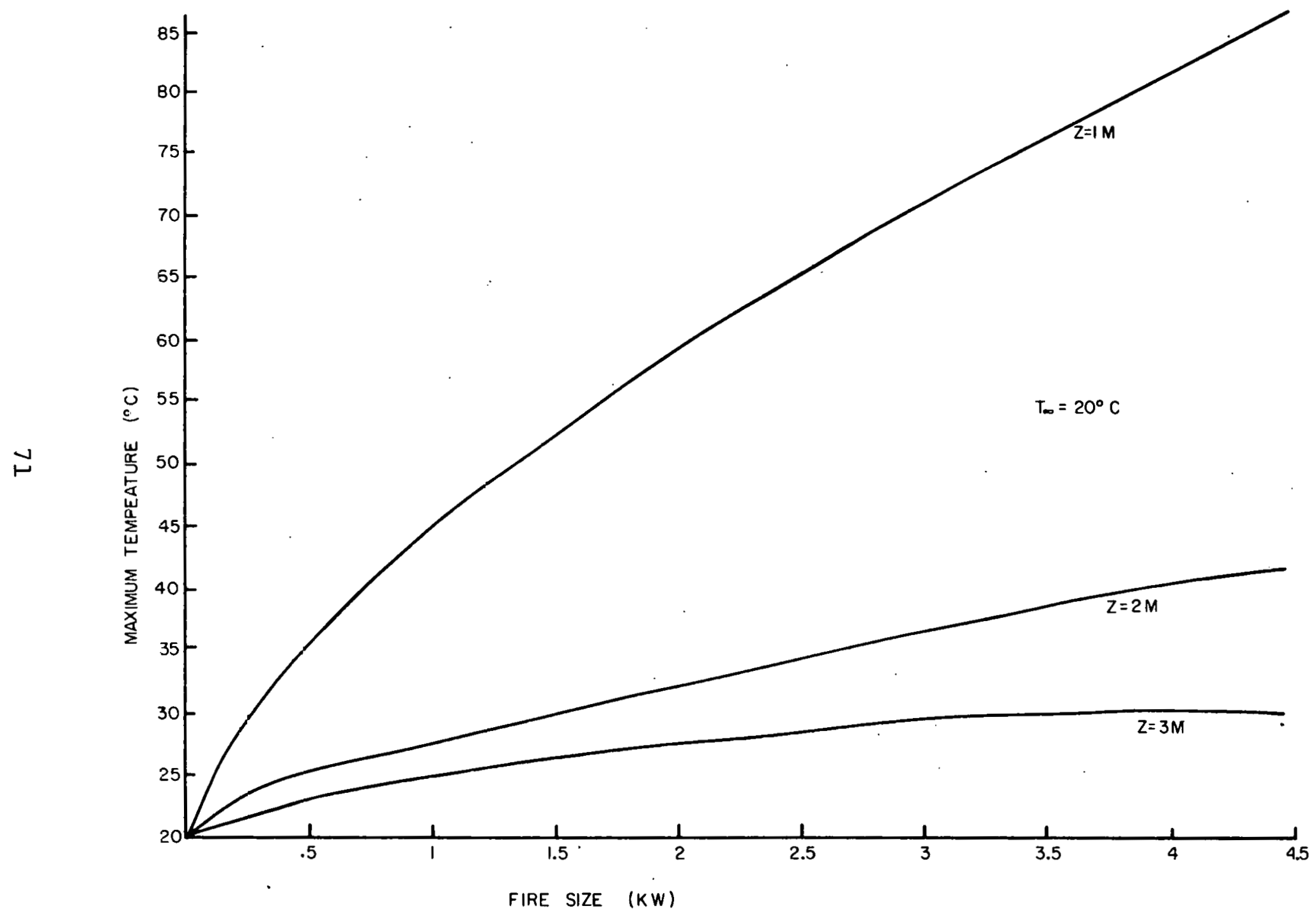

Figure 18: Maximum Temperature vs. Fire Size, at Various Elevations in the Plume 
The advantages of utilizing a heat source term to simulate the transport processes to a detector location include:

1. known scaling relationships between source plume and jet parameters

2. impact of environmental variables is quantifiable

3. temperature gradients easily detectable

1. localized tempcrature gradients can be used to predict actuation time of heat and smoke detectors

5. no corrosive gas releases/clean operation

6. easily calibrated instrumentation

7. heat source size can be varied with minimum detectable fire size requirement.

There are several possible disadvantages to using heat source element.s:

1. congested areas where clearance cannot be maintained between source and existing equipment

2. large areas with high ceiling heights may require large heat sources.

The types of heat sources which appear to be useful are gas type burners or electrical heat sources. Heat source design must include consideration of the following factors:

1. quantification of radiation losses from the source and plume, especially important in gas burners. 
2. The initial momentum of the gas jet in burner assemblies must be calculated to allow full plume development.

3. the heat source should be readily calibrated, and preferably adjustable over a range of convective outputs:

4. operations considerations include:

plant and personnel safety, positive method of precluding overtemperature development in the test area, etc.

The location of the heat source is of crucial importance. In this testing scheme it is expected that the analysis of smoke and heat transport need only be conducted at the initial system qualification tests and following any major compartment modifications. The initial selection methodology of test locations to evaluate smoke transport is as yet undefined. It is expected, however, that for a given detector a "worst case" situation can be located and transport to the detector established from that point. During development of the test methodology additional guidance would also become available.

Since temperature rise has been related to the actuation of smoke and heat detectors, sensing instruments are primarily thermocouples, due to their ease of use, availability, limited expense and ease of calibration. In addition, it may be useful to measure velocity, although additional work is required to determine the need and practicality of these measurements. 
Another issue which will need to be addressed is the acceptance criteria for this test. A minimum specified temperature increase as a function of the source strength or as a function of the temperature rise calculated for a quiescent atmosphere may be adequate criteria. The advantage of using temperature rise is again seen because it can be related to detector operating characteristics. Therefore, acceptance criteria can be performance bạsed:

It is clear that the utilization of a small heat source as a means for determining smoke/heat transport to a detector appears to be a reasonable solution to a very important problem. Additional work is needed to develop this concept further.

\section{Use of Test Gas to Simulate Plume}

Another approach to simulating the transport mechanisms of a fire plume and ceiling jet is to utilize a gas with a density selected to simulate the density and velocity profiles of a buoyant plume. The essential goal is to release a non-corrosive, non-toxic, easily detectable gas, . such that the gas will entrain ambient fluid and yield velocity, density and geometric profiles similar to a heated buoyant plume. Sufficiently good scaling relationships in terms of velocity and density profiles exist to evaluate the accuracy of such a method. Figures 18, 19, and 20 show density decay profiles for axisymetric and planar buoyant jets. 


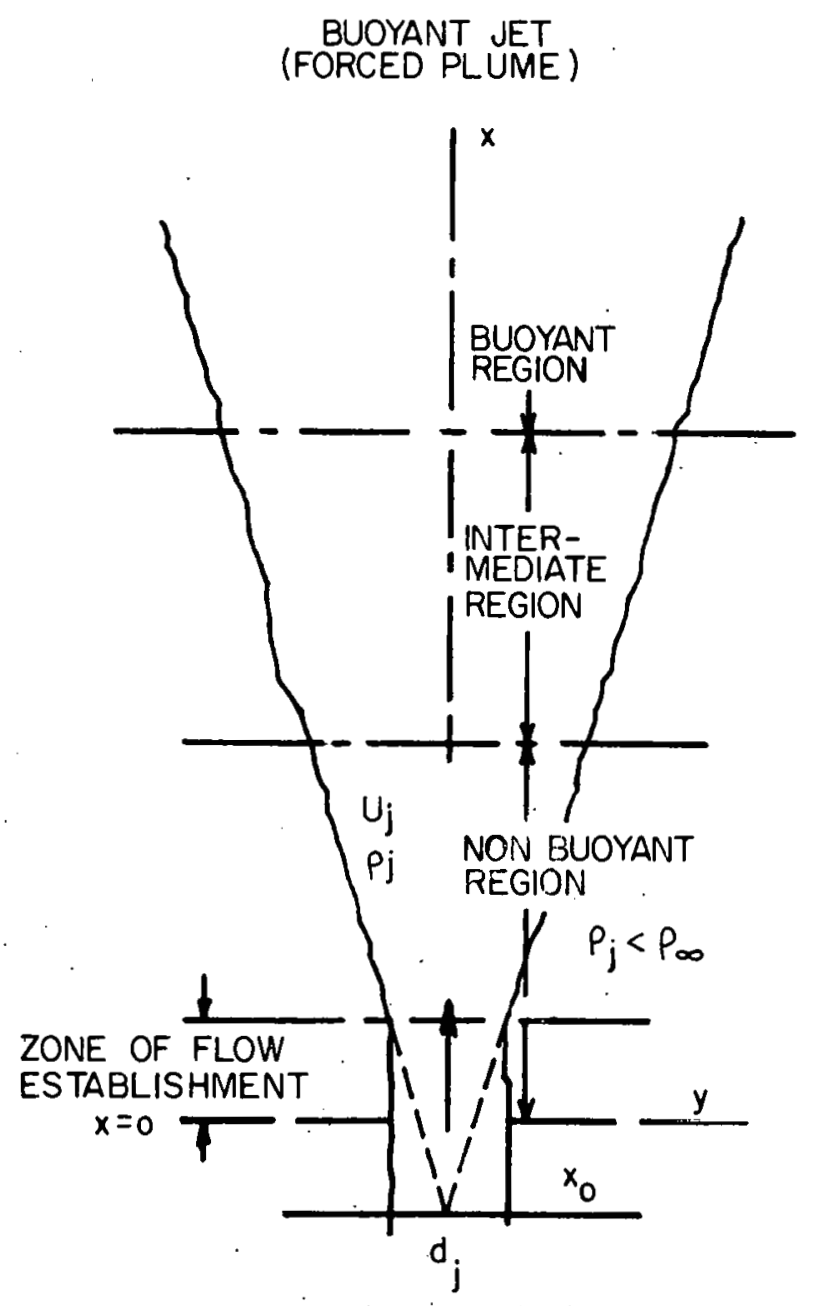

Figure 18: Schematic for Figures 19, 20 (45) 


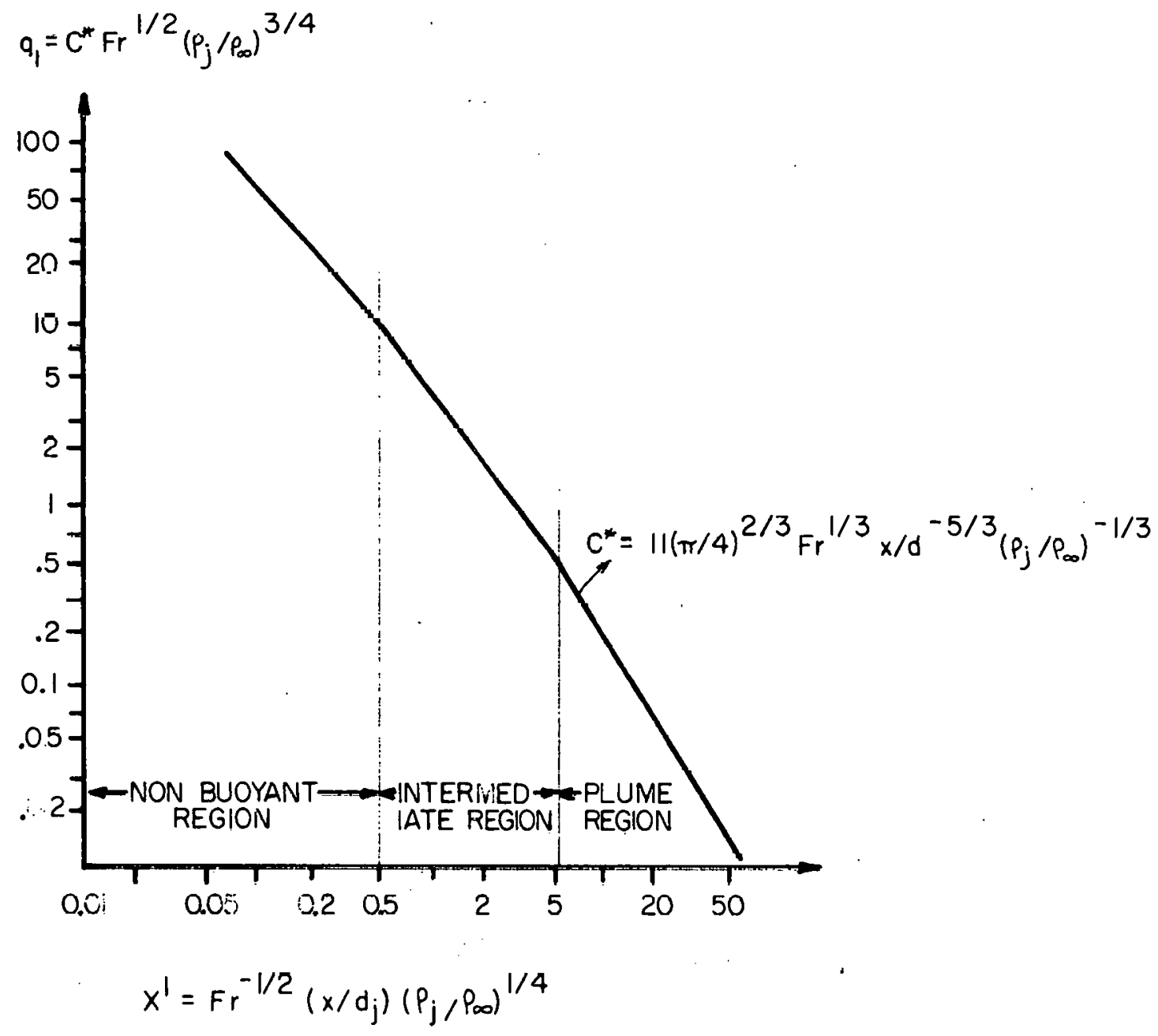

Figure 19: Centerline Plume Density for Buoyant Jets (44) (See Figure 18) 


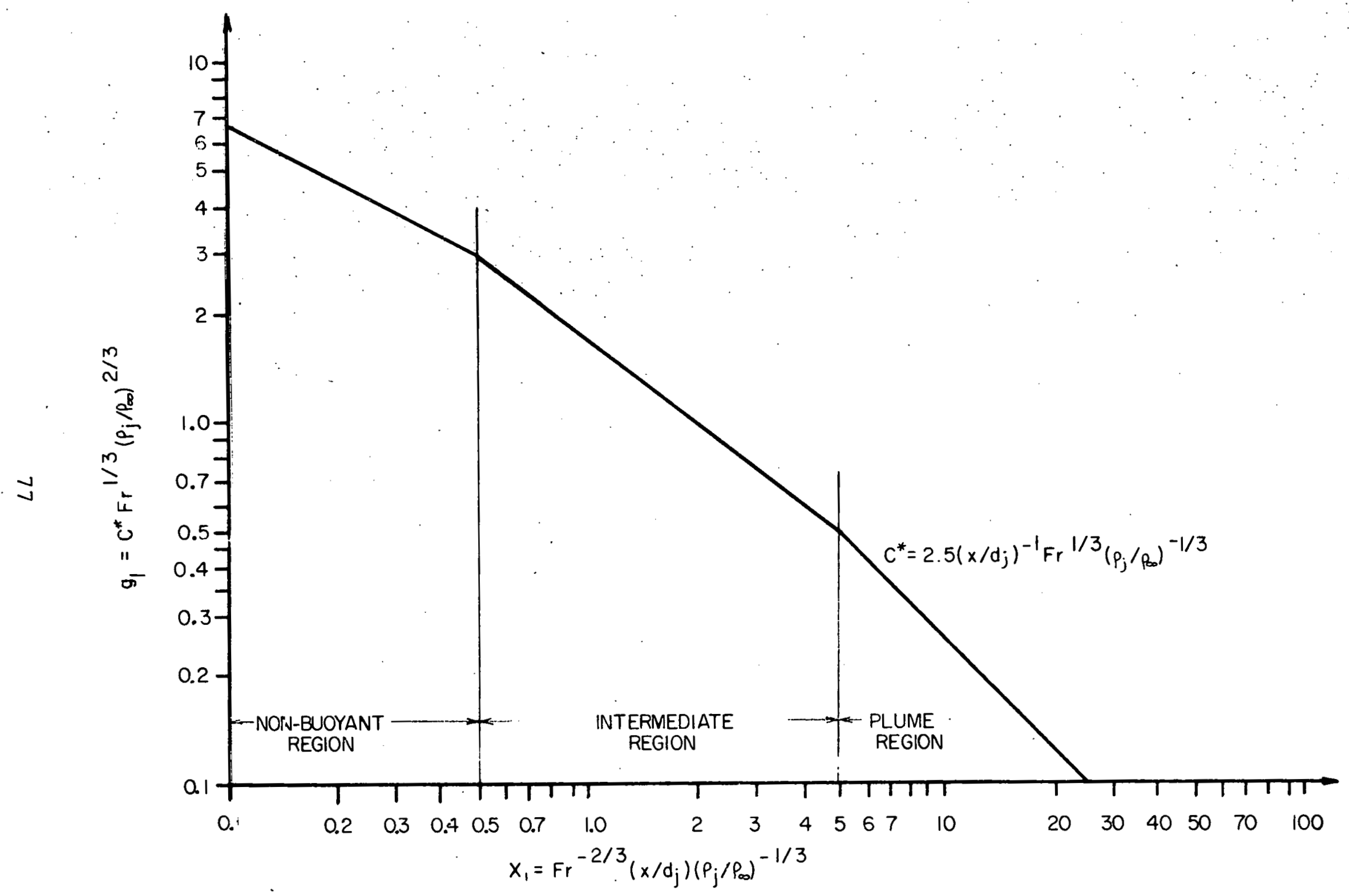

Figure 20: Centerline Density Decay (44), Reference Figure 18 
The test gas would need an initial density on the order of $.4 \mathrm{~kg} / \mathrm{m}^{3}$ and the following conditions of the gas could be varied to permit it to model a heated gas:

1. Initial gas velocity: This parameter would adjust the transition region from jet to purely buoyant plume. It would vary the ambient air entrained, and hence, the vertical density and velocity profiles and to scale the Grashof and Froude numbers.

2. Jet Size: The jet size could be adjusted to scale the Froude and Grashof numbers. This would enable, at the veny least, scaling of the plume portion of the phenomenon.

3. Gas mixture: The released gas mixture could be varied to provide for control of diffusion rates. This would enable adjustment of the rate of plume expansion radidly and ceiling jet dimensions.

The gas must be readily detectable and thus could be related to a density/ temperature profile at the point of detection to its concentration. It is not known it such a system can be readily devised to provide reproducible, simple testing. However, the advantages to such an in-situ test method are numerous. The key problems appear to be in the following areas:

1. estimation of entrainment and diffusion functions to simulate the density decay along the plume, and, more critically, in the ceiling layer. 
2. deșign of test gas mixture and sensory instrumentation to provide the necessary accuracy and reproducibility.

The use of a test gas as a method of in-situ evaluation of smoke and heat transfer to detectors is much less certain than the use of a heat source. Further, interpretation of the results of such a method is not straightforward. The key element in the development of such a method would be correlating sensed gas concentrations to the properties of the plume/jet. If this can be done for temperature gradient, for example., It is easy to see that this method can be related to actual: detector performance.

\section{Further Work}

In order to evaluate more specifically and in greater detail the various test methods proposed, the following additional work is required.

\section{Detector Response}

Smoke

1. Ensure that aerosol generators can be calculated readily and easily adjusted for various smoke signatures.

2. Determine recommended smoke signatures in terms of particle size distribution for different hazards.

3. Confirmatory research to validate recommended aerosol composition and methodology.

Heat

1. Develop localized heat source, calibrated to velocity 
temperature and rate of rise.

2. Select temperature and velocity profiles for calibration heat detector response (use expected flow conditions or established values for calibrating to a standard time constant).

3. Confirmatory testing to evaluate validity of methodology.

\section{Transport thenomena}

Heat Source Method

1. More detailed feasibility analysis is required, especially with respect to:
a. determination of minimum sensible temperature gradient. in a plant environment.
b. examination of exposure of equipment to temperature and velucity gradients.
r. examination of plant environmental conditions.

2. Perform full scale testing at Sandia facilities to:
a. establish recommended source strengths, related to selected hazard variables
b. establish impact of environmental conditions
c. verify scaling relationships for plume \& ceiling jet

3. Develop guidance for establishing a test procedure with respect to detection threshold requirements, suurce location, ctc.

4. Confirmatory testing of methodology in existing LWR facilities. 


\section{Gas Source Method}

Significantly more preliminary work is required to more fully evaluate the utility of this proposed method. Several immediate tasks are:

1. Establish physical feasibility of modeling plume density decay and ceiling jet formation, particularly with respect to:

a. impact of diffusion and entrainment

b. development of proper scaling relationships

c. identification of potential gas mixtures.

d. identification of concentration detection equipment.

e. develop relationships between gas concentration and density/temperature profiles.

2. The remainder of these tasks follow closely the tasks 1-4 for the heat source methodology. 


\section{CONCLUSIONS}

1. Adequate guidance for the design of fire detection systems in LWR facilities does not currently exist. Basic concepts and recent advances have not yet been incorporated into any document suitable for detection system design.

2. Current methods of in-situ testing are inadequate for the following reasons:

a. the impact of environmental variables on the transport of smoke and heat to the detection devices is generally ignored.

b. the hazard to be detected is not characterized in terms of a signature or in terms of transport properties.

c. the evaluation of detection systems does not include the various functional requirements for detection systems in terms of overall plant safcty.

3. There is insufficient understanding of the impact of the following environmental variables on detection system design:

- flow obstructions

- fluid reservoir formation (beam pockets)

- temperature stratification

- ventilation system construction

high

low

boundary layer formation

- high ceiling heights 
4. Current fire detection system design standards for LWR facilities are not verifiable.

5. Excellent theoretical models and scaling conditions exist for plume and ceiling jet for the spatial variation of temperature and velocity profiles.

6. Existing theoretical models are not sufficientily well: developed to address the problems of LWR environmental variables.

7. Current theoretical development on quantifying smoke signature formation and changes in smoke composition within the plume and ceiling jet is not sufficient to permit prediction of the smoke particle distribution at the detector:

8. Current adequate theoretical description of detector response exists for thermal, light obscuration, and ionization type detectors.

9. A theoretical description of the actuation of forward light scattering detectors has not been done but could be.

10. It is essential to develop an in-situ test method for the evaluation of fire detection system designs. Currently there is no adequate method of evaluating these systems.

11. In-situ test methods describing detection response to specified polydisperse aerosols exist and should be utilized in LWR facilities.

12. In-situ methods for evaluating smoke/heat transport mechanisms within LWR facilities have been proposed. It is essential that these methods physically replicate the important parameters describing plume/ceiling jet flow phenonema.

13. The reliability of fire detection systems can be adequately determined by available methods. 
14. Reliability criteria for detection systems need to be developed. This criteria should obviously be a function of the importance of the detection system to plant safety.

15. Detection systems currently are not designed with respect to criteria valid in LWR facilities. These criteria relate to the varying level of importance of the detertion systems to the overall safety of the plant. Some mechanism is required to fdenlify tlie function of the detection system with respect to plant safety.

16. Probablistic models of detection system actuation appear to have great potential in characterizing the widely variable environmental and installation conditions. However, full scale tests are required to more fully understand the importance of these parameters. 


\section{RECOMMENDATIONS}

1. Guidance to be used in the design and evaluation of fire detection systems should be prepared. This guidance should incorporate recent advances and well established physical principles. Particular attention should be paid to the effect of environmental variables on the flow fields of buoyant plumes and ceiling jets.

2. Full scale tests should be conducted to assess the impact of environmental and hazard variables on the effectiveness of fire detection systems in LWR facilities. As a minimum, the following variables should be examined: source strength (smoldering, flaming fires) ceiling height ambient temperature stratification high combustion rates deep beam pockets ventilation system flow separation flow obstructions cable trays

3. Results of full scale tests should be synthesized into design guidance for LWR facilities.

4. Development of the proposed in-situ test methods should continue with particular emphasis on heat source systems. Initially, a more detailed feasibility study should be conducted, followed by an initial scoping test program. These tests could be readily conducted in conjunciton with the tests 1 isted in Item 2. Development of the proposed gas source should also be pursued as discussed in section $V$. 
5. Full scale tests are necessary to confirm acceptance criteria and test standardization criteria for the proposed in-situ test methods.

6. A method should be developed to quantify the fire source size which must be detected and to provide an indication of the permissible time interval for its detection. This very important problem is basic to the development of verifiable acceptance criteria for desigri. The minimum detectable source size should relate the importance of the detection system to overall. plant safey. Such a scheme can be developed with available data and should be verified by confirmatory testing. 


\section{REFERENCES}

1. Standard for the Installation, Maintenance and Use of Proprietary Protective Signaling Systems, NFPA \# 720, National Fire Protection Association, Boston, Massachusetts, 02210.

2. Standard on Automatic Fire Detectors, NFPA \# 72E, National Fire Protection Association, Boston, Massachusetts, 02210.

3. "Standard Review Plan 9.51," Nuclear Regulatory Commission, Washington, D.C.

4. Regulatory Guide 1.120, Nuclear Regulatory Commission, Washington, D.C.

5. Berry, D.L., "Nuclear Power Plant Protection: Fire Detection (Subsystems Study TASK 2)," Sandia Laboratories, Albuquerque, March, 1979.

6. Smoke Detectors, Combustion Products Type for Fire Protective Signaling Systems, UL167, Underwriters Laboratories, Northbrook, 111 ., November 1974.

7. Smoke Detectors, Photoelectric Type for Fire Protective Signaling Sys tems, UL168, Underwriters Laboratories, Northbrook, I11.., Jan. 1976.

8. Heat Detectors, Single and Multiple Station, UL539, Underwriters Laboratories, Northbrook, 1978.

9. Smoke Detectors for Fire Protection Signaling Systems, UL268, Underwriters Laboratories, Northbrook.

10. Approval Standards; Smoke Actuated Detectors for Automatic Fire Alarm Signaling, Factory Mutual Research: Norwood, Feb. 1976.

11. Lee, T.G.K., "An Instrument to Evaluate Installed Smoke Detectors," NBSIR 78-1430, NBS, Washington, D.C., February, 1978.

12. Nuclear Plant Fire Protection Functional Responsibilities, Administrative Controls and Quality Assurance, Attachment 6, Supplementary Guidance, Nuclear Regulatory Commission, Washington, D.C.

13. Berry, D.L., "Nuclear Power Plant Protection, Philosophy and Analysis," Sandia National Laboratories, May, 1980.

14. Benjamin, I.A., "Detector Response in Large Buildings," paper presented at "Workshop on Engineering Applications of Fire Technology," April 16-18, 1980, NBS, Washington, D.C. 
References (continued)

15. Moelling, D.S., et. al., "Reliability of Fire Protection Systems in Nuclear Power Plants," Procedings ANS/ENS Topical Meeting, Thermal Reactor Safety, April 6, 9, 1980, Knoxville, Tennessee.

16. Alvarez, N.J., and Hasegawa, H.K., "Fire Hazard Analysis for Fusion Energy Experiments," Fire Safety Journal, Vo1. 2, 197.9-80, pp. 191-211.

17. Aggarwal, K.K., et. al., "Reliability Evaluation, A comparative Study of Different. Techniques," Micrnelectronics and Reliability, Vol. 14 Pergamon Press, 1975.

18. Nakayáwa, T., et. al., "Reliability Analysis of Intermittently Uscd Systems When Failures are Detected only During a Usage Period," Microelectronics and Reliability, Vol. 5, Pergamon Press, 1976.

19. Nieuwhof, G.W., "An Introduction to Fault Tree Analysis with Emphasis on Failure Rate Evaluation," Microelectronics and Reliability, Vol 14, Pergamon Press, 1975.

20. Proctor, C.L., et. al., "Fault Tree Analysis with Probability Evaluation Proceedings," 1978 Annual Reliability and Maintainability Symposium, IEEE, 1978.

21. Rickers, H.C., "Reliability Modeling of Smoke Detectors," NBS-GCR-79-160, NBS, Washington, D.C., March, 1979.

22. Rickers, H.C., "Residential Smoke Detector Reliability Handbook, Section 1: Parts Stress Analys1s," NBS-GCR-79-161, NBS, Washinglun, D.C., f'ebruary, 1969.

23. Rickers, H.D., "Residential Smoke Detector Reliability. Handbook, Section 2: System Reliability Evaluation Techniques, Section 3: Component Screening Test Techntques," NBS-GCR-79-162, NBS, Washington, D.C. March, 1979.

24. Single and Multiple Station Smoke Detectors, UL217, Underwriters Laboratories, Northbrook, 1978.

25. Bukuwski, R.W., and Mulholland, li.W., "'imoke Detector Design and Smoke Properties," NBSTN 973, NBS, Washington, D.C., Nov. 1978.

26. Watts, J., "A Theoretical Rationalization of the Goal Oriented Systems Approach," Department of Fire Protection Engineering, University of Maryland, College Park, MD, 1978.

27. Yao, C., "Application of Sprinkler Technology," paper presented at The Workshop on Engineering Applications of Fire Technology, April 16-18, NBS, Washington, D.C. 
References (continued)

28. Beyler, C., "The Interaction of Fire and Sprinklers," Department of Fire Protection Engineering, University of Maryland, College Park, September, 1977.

29. Litton, D.C., "A Mathematical Model for Ionization Type Smoke Detectors and the Reduced Source Approximation," Fire Technology, Vol. 13, No. 3, November, 1977. pp. 266-282.

30. Litton, D.C., "Optimizing Ionization Type Smoke Detectors," Fire Technology, Vol. 15, No. 1, February, 1979, pp. 25-43.

31. Zerull, R., "Shape Dependence of Light Scattering Behavior of Dust Particles, NBSIR 76-1931, NBS, Washington, D.C., June, 1976.

32. Bankston, C.P., et. al., "Review of Smoke Particulate Properties Data for Burning Natural and Synthetic Materials," NBS-GCR-78-147, NBS, Washington, D.C., May 1878.

33. Hodkinson, J.R., "The Optical Measurement of Aerosols," Aerosol Science, edited by C.N. Davies, Academic Press, New York, 1966, pp. 287-357.

34. Hodkinson, J.R., and Greenfield, J.R., Applied Optics, 4, 11, 1463, November, 1965.

35. Japanese Association of Fire Science and Engineering, "Researches in Smoke Properties in Japan," Fire Research and Safety, National Bureau of Standards, Washington, D.C., 1979.

36. Alpert, R.L., "Turbulent Ceiling Jet Induced by Large Scale Fires," Comb. Science and Technology, Vol. II, pp. 197-213, 1975.

37. Alpert, R.L., "Response Time of Ceiling-Mounted Fire Detectors," Fire Technology, Vol. 8, No. 3, pp. 181-195, August, 1972.

38. Zukowski, E.E., and Kubota, T., "An Experimental Investigation of the Heat Transfer from a Buoyant Gas Plume to a Horizontal Ceiling; Part 2: Effects of Ceiling Layer," NBS-GCR-77-98, NBS, Washington, D.C., September, 1975.

39. Veldman, C.C., Kubota, T., and Zukowski, E.E., "An Experimental Investigation of the Heat Transfer from a Buoyant Gas Plume to a Horizontal Ceiling-Part 1, Unobstructed Ceiling," NBS-GCR-77-97, NBS, Washington, D.C. June, 1975.

40. Heskestead, G., Delichatios, M.A., "The Initial Convective Flow in Fire," 15th Symposium on Combustion, The Combustion Institute, Pittsburg, PA. pp. 1113-1123. 
References (continued)

41. Cooper, L.Y., "Calculating Escape Time From Fires," Procedings of Workshop on Engineering Applications of Fire Technology, Gaithersburg, April, 1980.

42. Heskestead, G., and Delichatsios, M.A., "Environments of Fire DetectorsPhase I: Effect of Fire Size, Ceiling Height and Material," Vol. 2 Analysis, NSB-GCR-77-95, NBS, Washington, D.C., July, 1977.

43. Heskestead, G., and Delichatsios, M.A., "Environments of Fire Detectors-Phase 2: Effect of Ceiling Configuration," Vol. 1 Measurements, NBS-GCR-78-128, NBS, Washington, D.C., June, 1978.

44. Heskestead, G., and Delichatsios, M.A., "Evnironments of Fire Detectors-Phase II: Effect of Ceiling Configuration" Vol. 2, Analysis, NBS-GCR-78-129, NBS, Washignton, D.C., June, 1978.

45. Schetz, J.A., Injection and Mixing in Turbulent Flow, Vol. 68, Progress in Astronautics and Aeronautics, M. Summerfield, Ed., AIIA, 1980/

46. Heskestead, G., and Delichastsios, M.A., "Environments of Fire Detectors-Phase 1: Effect of Fire Size, Ceiling Height, and Material," Vol. 1 Measurements," NBS-GCR-77-86, NBS, Washignton, D.C., May 1977.

47. Bukowski, R.W., "Investigation of the Effects of Heating and Air Conditioning on the Performance of Smoke Detectors in Mobile Homes," NBSIR 79-1915, NBS, Washington, D.C., October, 1979.

48. Industrial Ventilation, A Manual of Recommended Practice, '13th Edition, American Conference of Governmental Industrial Hygenists, Edwards Bros., 1974.

49. Fuchs, N.A., The Mechanics of Aerosols, MacMillan Company, New York, 1964.

50. Miyama, J., et. al., "False Alarm of Smoke Detectors," Fire Research and Safety, NBS, Washignton, D.C., November 1979. 
DISTRIBUTIOIN :

$$
\text { TID-4500 - UC-78 (197 Copies) }
$$

J. H. Carlson, $\mathrm{NE}-540$ (5)

Office of Nuclear Power Systems

U. S. Department of Energy

Mail Stop B-107

Washington, DC 20545

J. D. Griffith, Acting Director

Office of Nuclear Power Systems, NE-540

U. S. Department of Energy.

Mail Stop B-107

Washington, DC 20545

A. C. Millunzi, Team Leader

Safety Research and Development Team, NE-540

Office of Nuclear Power Systems

U. S. Department of Energy

Mail Station $B-107$

Washington, DC 20545

J. Yevick, NE-540

Safety Research and Development Team

Office of Nuclear Power Systems

U. S. Department of Energy

Mail Station B-107

Washington, DC 20545

Leo Beltracchi

U. S. Nuclear Regulatory 'Commission'

Division of Systems Safety $P-350$

Office of ivuclear Reactor Regulations

Washington, DC. 20555

Raymond DiSalvo, Branch Chief

operations Safety Research

U. S. Nuclear Regulatory Commission

Mail stop 1130ss

Washington, DC 20555

George Knighton, Branch Chief

Research \& Standards Coordination

U. S. Nuclear Regulatory Commission

Mail Stop P-538

washington, DC 20555 
Distribution (cont'd) :

R. Minogue, Director

Office of Nuclear Regulatory Research

U. S. Nuclear Regulatory Commission

Mail stop ll30ss

Washington, DC 20555

D. Notley

Office of Nuclear Regulatory Research

U. S. Nuclear Regulatory Commission

Mail stop ll30sS

Washington, DC 20555

R. Fejt

Office of Nuclear Regulatory Research

U. S. Nuclcar Regulatory Commission

Mail stop 113055

Washington, DC 20555

Robert L. Ferguson

Division of Systems Safety

Office of Nuclear Reactor Regulation

U. S. Nuclear Regulatory Commission

Washington, DC 20555

D. Okrent

University of California

Chemical, Nuclear, and Thermal Engineering

5532 Boelter Hall

Los Angeles, CA 90024

W. Lowenatein

Electric Power Research. Institute

3412 Hillview Avenue

P. O. BOX 10412

Palo Alto, CA 94303

K. W. Dungan (20)

Professional Loss Control

P. O. Box 446

Oak Ridge, TN. 37830

T. T. Rryan

Professor and Department Head

Department of Fire Protection Engineering

University of Maryland

College Park, MD 20742

J. A. Milke

Research Assistant

Department of Fire Protection Engineering

University of Maryland

College Park, MD 20742 
Distribution (cont'd) :

D. Perrault

Fire Protection Engineer

Bechtel Power Corp.

15740 Shady Grove Road

Gaithersburg, MD 20760

E. A. Sawyer

Yankee Atomic Electric

1671 Worchester Road

Framingham, MA. 01701

Chris Volman

Fire Protection Engineer . $\ldots, \ldots$

Paducah Gaseous Diffusion Plant

P. O. Box 1410

Paducah, KY 42001

R. Bukowski

Center for Fire Research

National Bureau of Standards

Washington, DC. 20234

N. Chekotis

Pytronics Corp.

8 Ridgedale Avenue

Cedar Knolls NJ 07927 .

G. Patrissi

Florida Power Corp.

Crystal River Nuclear P.lant

P. O. Box 1240

Crystal River, FL 32629

R. Schmiedel

Flurial Power corporation

P. O. Box 14042

St. Petersburg, FL 33733

W. Klein

Florida Power \& Light

Turkey Point Nuclear Plant

P. O. Box 529100

Miami, FL 33152

D. Keigher

Fire Protection Consultant

Los Alamos Scientific Laboratory

P. O. Box 1663

Los Alamos, NM 87545 
Distribution (cont'd):

D. Rosh

Consolidated Edison of N.Y.

Room 1014

4 Irving Place

New York, NY 10003

E. Budnick

Center for Fire Research

National Bureau of Standards

Washington, DC 20234

J. D. Allen, P.E.

Director, Fire Protection tingineering

Insurance Company of North America.

Loss Control Division

1600 Arch Street

Philadelphia, PA 19103

L. R. Hathaway, Manager

Public Utility unit

$M$ \& $M$ Protection Consultants

222 South Riverside Plaza

Chicago,. II 60606

H. K. Hasegawa

Fire Science Group, Hazards Control Department. University of California

P. O. Box 5505, I-442

Livermore, CA 94550

B. J. Gerwe

Fire Protection Engineer

Gilbert Associates, Inc.

Reading, PA 19603

D. E. Roland

Susquehanna S.E.S.

Pennsylvania Power \& Light co.

P. O. Box 467

Berwick, PA 18603

R. J. O'Laughlin

Union Carbide Corporation

Nuclear Division

Mail stop 003

Post Office Box $Y$

oak Ridge, TN 37830 
Distribution (cont'd) :

ก. Perrault

Fire Protection Engineer

Bechtel Power Corp.

15740 Shady Grove Road

Gaithersburg, MD 20760

E. A. Sawyer

Yankee Atomic Electric

1671 Worchester Road

Framingham, MA 01701

Chris Volman

Fire Protection Engineer

Paducah Gaseous Diffusion Plant

P. O. Box 1410

Paducah, KY 42001

R. Bukowski

Center for Fire Research

National Bureau of Standards

Washington, DC 20234

N. Chekotis

Pytronics Corp.

8 Ridgedale Avenue

Cedar Knolls; $: \mathrm{NJ}: 07927$

G. Patrissi

Florida Power Corp.

Crystal River Nuclear Plant

P. O. Box 1240

Crystal River, FL 32629

R. Schmiedel

florida Hower Corporation.

P. O. Box 14042

St. Petersburg, FL 33733

W. Klein

Florida Power \& Light

Turkey Point Nuclear Plant

P. O. Box 529100

Miami, FL 33152

D. Keigher

Fire Protection Consultant

Los Alamos Scientific Laboratory

P. O. Box 1663

Los Alamos, NMI

87545 
Distribution (cont'd):

D. Rosh

Consolidated Edison of N.Y.

Room 1014

4 Irving Place

New York, NY 10003

E. Budnick

Center for Fire Research

National Bureau of Standards

Washington, DC 20234

J. D. Allen, P.E.

Director, Fire Protection Engineering

Insurance Company of North America.

Loss Control Division

1600 Mroh street

Philadelphia, PA 19103

L. R. Hathaway, Manager

Puolic Utility Unit

$M \& M$ Protection Consultants

222 South Riverside PIaza

Chicago, IL 60606

H. K. Hasegawa

Fire Science Group, Hazards Control Department University of California

P. O. Box 5505, L-442

Livermore, CA 94550

B. J. Gerwe

Fire Protection Engineer

Gilbert Associates, Inc.

Reading, PA 19603

D. E. Roland

Susquehanna S.E.S.

Pennsylvania Power \& Iight Co.

P. O. Box 467

Berwick, PA 18603

R. J. O'Iraughlin

Union Carbide Corporation

Nuclear Division

Mail Stop 003

Post Office Box $Y$

Oak Ridge, TN 37830 
Distribution (cont'd):

J. Echternacht, Manager.

Wormald Firc Engineeriny

5255 Langfield Road, suite $F$

Houston, TX 77040

B. Melly

Fire Protection Engineer

Systems Division

Black \& Veach

P. O. Box 8405

Kansas City, MO 64114

D. Harbert

United Engineers \& Constructors

c/o Carolina Power \& Light.

Brunswick Steam Electric Plant

P. O. Box 1087

Southport, NC 28461

R. R. Cholin, President

Firetek Corp.

53 Thomas Road

Hawthorne, NJ 07306

J. Corcoran

Niagara Mohawk Power Corp.

300 Erie Boulevard West

Syracuse, NY 13202

J. L. Dymek

Florida Power \& Light

P. O. Box 529100

Miami, FL 33010

H. Taylor

Fire Protection Specialist

Power Generation Department

Georgia Power Co.

230 Peachtree Street, 16th Floor

Atlanta, GA 30302

A. D. J. Sanchez, Mechanical Engineer

Generation Engineering Department

Portland General Electric

121 S.W. Salmon Street

Portland, OR 97204 
Distribution (cont'd) :

P. D. Lund

Society of Fire Protection Engineers

60 Batterymarch street

Boston, MA 02110

J. Stamp

F. E. Moran, Inc.

P. O. Box 551

Northbrook, IL 60062

R. Thompson, Supervisor

Fire Protection Engineering

Tennessee Valley Authority

1650 Chestnut Street Tower II

chattanooga, TN 37401

R. M. H. Terrier, Director

Loss Prevention

Virginia Electric \& Power Co.

1 James River Plaza

P. O. Box 26666

Richmond, VA 23261

G. W. Powell

Baltimore Gas \& Electric Co.

P. O. Box 1475

Baltimore, MD 21203

B. Cohn

Gage-Babcock

135 Addison Avenue

Elmliurgt, IL 60126

R. Pape

IIT Research Inst.

Chemical Division

$10 \mathrm{~W}$. 35th street

Chicago, IL 60616

J. Rockett

Center for Fire Research

National Bureau of Standards

Washington, DC 20234

B. Williamson

507 Davis Hall

University of california

Berkeley, CA 94720 
Distribution (cont'd):

Energy Research \& Technology Division

U. S. Deparlitit uf Energy

Albuquerque Operations Office

Albuquerque, NM 87185

Attn: D. L. Krenz, Director

R. L. Clark

4400 A. W. Snyder

4440 G. R. Otey

4410 D. J. McCloskey

4414 G. B. Varnado

4414 D. L. Berry

4442 W. A. Von Riesemann

4442 D. Dube

4442 L. J. Klamerus

4443 D. A. Dahlgren

4443 P. Shea (20)

4443 J. I. Sprung

5513 D. W. Larson

5513 M. R. Baer

5513 D. D. Cline

8214 M. A. Pound

3141 L. J. Erickson (5)

3151 W. L. Garner (3)

DOE/TIC (Unlimited Release) 